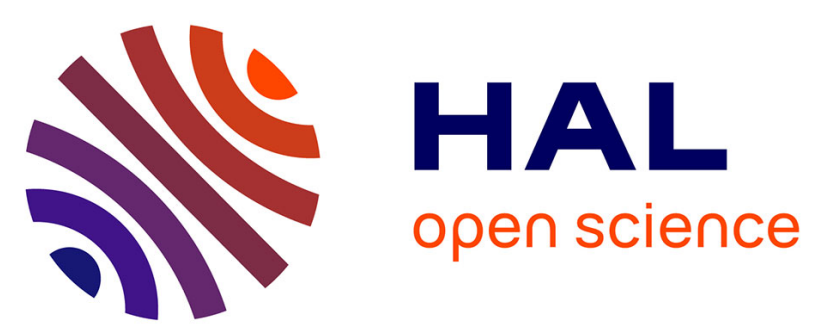

\title{
In vitro evaluation of electrochemically bioactivated Ti6Al4V 3D porous scaffolds
}

Alexandr Myakinin, Amanzhol Turlybekuly, Alexander Pogrebnjak, Adam Mirek, Mikhael Bechelany, Iryna Liubchak, Oleksandr Oleshko, Yevheniia Husak, Viktoriia Korniienko, Katarzyna Leśniak-Ziólkowska, et al.

\section{To cite this version:}

Alexandr Myakinin, Amanzhol Turlybekuly, Alexander Pogrebnjak, Adam Mirek, Mikhael Bechelany, et al.. In vitro evaluation of electrochemically bioactivated Ti6Al4V 3D porous scaffolds. Materials Science and Engineering: C, 2021, 121, pp.111870. 10.1016/j.msec.2021.111870 . hal-03258069

\section{HAL Id: hal-03258069 https://hal.science/hal-03258069}

Submitted on 11 Jun 2021

HAL is a multi-disciplinary open access archive for the deposit and dissemination of scientific research documents, whether they are published or not. The documents may come from teaching and research institutions in France or abroad, or from public or private research centers.
L'archive ouverte pluridisciplinaire HAL, est destinée au dépôt et à la diffusion de documents scientifiques de niveau recherche, publiés ou non, émanant des établissements d'enseignement et de recherche français ou étrangers, des laboratoires publics ou privés. 


\title{
In vitro evaluation of electrochemically bioactivated Ti6Al4V 3D porous scaffolds
}

Alexandr Myakinin ${ }^{\mathrm{a}}$, Amanzhol Turlybekuly ${ }^{\mathrm{b}}$, Alexander Pogrebnjak ${ }^{\mathrm{c}, \mathrm{d}}$, Adam Mirek ${ }^{\mathrm{e}, \mathrm{f}}$, Mikhael Bechelany ${ }^{\mathrm{e}}$, Iryna Liubchak ${ }^{\mathrm{c}}$, Oleksandr Oleshko ${ }^{\mathrm{c}}$, Yevheniia Husak ${ }^{\mathrm{c}}$, Viktoriia Korniienko $^{\mathrm{c}}$, Katarzyna Leśniak-Ziółkowska ${ }^{\mathrm{g}}$, Dmitry Dogadkin ${ }^{\mathrm{b}}$, Rafał Banasiuk ${ }^{\mathrm{h}, \mathrm{i}}$, Roman Moskalenko $^{c}$, Maksym Pogorielovec,, Wojciech Simka ${ }^{\mathrm{g}, \mathrm{j}}$ *

${ }^{a}$ D. Serikbayev East Kazakhstan State Technical University, F02K6B2 Oskemen, Kazakhstan

${ }^{b}$ Nazarbayev University, Z05H0P9 Nur-Sultan, Kazakhstan

${ }^{c}$ Sumy State University, Medical Institute, 40018 Sumy, Ukraine

${ }^{d}$ al-Farabi Kazakh National university, 050040, Almaty, Kazakhstan

e Institut Européen des Membranes, IEM, UMR-5635, University Montpellier, CNRS, ENSCM, 34095 Montpellier CEDEX 5, France

${ }^{f}$ Nalecz Institute of Biocybernetics and Biomedical Engineering PAS, 02-109 Warsaw, Poland

${ }^{g}$ Silesian University of Technology, Faculty of Chemistry, 44-100 Gliwice, Poland

${ }^{h}$ NanoWave, 02-676 Warsaw, Poland

${ }^{i}$ Institute of Biotechnology and Molecular Medicine, 80-172 Gdansk, Poland

${ }^{j}$ NanoPrime, 32-900 Dębica, Poland

Keywords: 3D printed Ti614V scaffolds; plasma electrolytic oxidation, antibacterial coating, Ag nanoparticles

\begin{abstract}
Triply periodic minimal surfaces (TPMS) are known for their advanced mechanical properties and are wrinkle-free with a smooth local topology. These surfaces provide suitable conditions for cell attachment and proliferation. In this study, the in vitro osteoinductive and antibacterial properties of scaffolds with different minimal pore diameters and architectures were investigated. For the first time, scaffolds with TPMS architecture were treated electrochemically by plasma electrolytic oxidation (PEO) with and without silver
\end{abstract}


nanoparticles (AgNPs) to enhance the surface bioactivity. It was found that the scaffold architecture had a greater impact on the osteoblast cell activity than the pore size. Through control of the architecture type, the collagen production by osteoblast cells increased by $18.9 \%$ and by $43.0 \%$ in the case of additional surface PEO bioactivation. The manufactured scaffolds demonstrated an extremely low quasi-elastic modulus (comparable with trabecular and cortical bone), which was 5 - 10 times lower than that of bulk titanium (6.4-11.4 GPa vs 100-105 GPa). The AgNPs provided antibacterial properties against both gram-positive and gram-negative bacteria and had no significant impact on the osteoblast cell growth. Complex experimental results show the in vitro effectiveness of the PEO-modified TPMS architecture, which could positively impact the clinical applications of porous bioactive implants.

\section{Introduction}

Additive manufacturing opens new opportunities for the development of bone scaffolds with different architectures obtained from a wide range of metals. The architecture, topology and mechanical properties of additively manufactured (AM) meta-biomaterials are still under intensive investigation [1]. The new scaffold design and its surface bioactivity enhancement still need improvement [1-4].

One of most popular materials used for titanium implant production is Ti6Al4V alloy. Its Young's modulus is $100-105 \mathrm{GPa}$, which is superior to the cortical (18.6-20.7 GPa) and trabecular (10.4-14.8 GPa) bones [5-7]. Young modulus mismatches cause stress-shielding syndrome followed by implant-associated complications and implant failure [5,8-11]. The bioinspired scaffolds with triply periodic minimal surface (TPMS) architecture offer the ability to control the mechanical properties by varying the porosity, wall thickness and cell size of AM devices to resolve stress-shielding syndrome complications [4]. 
TPMS are known for their advanced mechanical properties and are wrinkle-free with a smooth local topology. The smoothness results from a local area minimization principle, which causes the disappearance of the mean curvature and the Young-Laplace pressure [12]. The scaffolds with TPMS architecture are advantageous at that stage due to zero mean curvature. It has been proposed that the tissue growth process is curvature-driven [13-15]. This means that growth increases with local curvature, resulting in a round opening regardless of the initial substrate shape. Moreover, porous implants might have osteoconductive properties, as some studies have suggested [14]. The mass transport and mechanical properties of primitive (P), I-WP (I), gyroid (G), and diamond (D) structures were investigated by F. S. L. Bobbert [15]. They showed extremely high fatigue resistance compared to other AM structures (60\% of their yield stress). Moreover, high rate mass transport properties promise high osteoconductive properties. Despite numerous studies $[1,2,4,14-20]$, in which mass transport, mechanical properties, and surface precipitation of scaffolds with TPMS architecture were investigated, additional studies are needed to gain knowledge regarding the dependence of the osteoconductive properties on the minimal pore diameter. The parameter of minimal pore diameter impacts tissue growth as well as scaffold surface properties [21]. Previous studies have shown the successful application of TPMS structures in orthopedics and bone regeneration [15,22-26]. However, there are limited data regarding osteoinductivity and osteoconductivity with respect to minimal pore diameter and TPMS structure types.

The bioactivity of implants strongly influences their surface properties. One methodology to improve the bioactivity is to enrich the implant surface with elements such as calcium and phosphorus. Materials based on calcium and phosphates can provide additional stimulation for osteogenic cell adhesion and proliferation [27-29]. Different amorphous, hydroxyapatite and brushite coatings encourage osteoblast adhesion, alkaline phosphatase 
(ALP) and collagen synthesis and enhance MSC differentiation [30-33]. Plasma electrolytic oxidation (PEO) is a promising, precise and effective method to obtained Ca-P ceramic coatings for orthopedics and dental implants [34]. PEO allows for the incorporation of chemical compounds soluble in water or ceramic particles from the anodizing solution. This method can reduce the treatment time and cost and provide strong adhesion between the metallic substrates and the coatings, which have been found to resist failure during the implant service time [35]. Despite the chemical composition, the PEO surface can provide additional micropores to enhance cell adhesion and tissue growth [36]. There are many studies of nanoparticle (NP) incorporation, particularly silver NPs, in metal implants during the PEO process $[17,37]$ to provide additional antibacterial properties. Implant-associated infections carry a high risk of unsuccessful medical treatment, especially the formation of resistant bacterial biofilms [38]. Targeted delivery to the peri-implant area is beneficial to reaching therapeutic levels of antibacterial drug concentrations [17,39]. Silver nanoparticles show a pronounced bactericidal activity for eukaryotic cells, which affects osseointegration. This property promoted the widespread use of silver in orthopedics [17,39]. Ag is widely used as an antibacterial coating due to its excellent antimicrobial properties against a wide variety of microbes, including gram-positive and gram-negative bacteria [40]. However, antibacterial AgNP coatings with high concentrations of $\mathrm{Ag}$ have also been found to be cytotoxic and inhibit osteointegration $[41,42]$, and it is therefore required to balance the NP concentration.

The plasma electrolytic oxidation of titanium or its alloys is broadly described in the literature; however, there is a lack of information on the anodization of titanium-based SLA printed scaffolds [43,44]. Anodization of 3D scaffolds with different architectures was performed in solutions based on calcium acetate and calcium glycerophosphate or sodium phosphate monobasic dihydrate, ethylenediaminetetraacetic, and sodium hydroxide in 
different electrical modes. The obtained layers were uniform and composed of oxides with incorporated calcium and phosphorus.

In the present article, we demonstrated the in vitro behavior of 3D printed scaffolds with different TPMS architectures, with a focus on directed bone regeneration and achievement of desirable mechanical properties (similar to natural bone). Additionally, for the first time, we showed that antibacterial coatings can be formed on 3D scaffolds using the PEO process in a solution containing Ag nanoparticles.

\section{Materials and methods}

\subsection{Triply periodic minimal surfaces and production of scaffolds}

The samples were produced from medical certificated DIN EN ISO 22674 Rematitan ${ }^{\circledR}$ CL powder (Ispringen, Germany). The chemical composition of the powder was $\mathrm{Ti}-90 \%, \mathrm{Al}$ $-6 \%, \mathrm{~V}-4 \%$, and the other elements were $\mathrm{N}, \mathrm{C}, \mathrm{H}, \mathrm{Fe}$, and $\mathrm{O}<1 \%$ (weight $\%$ ). The scaffolds with TPMS architecture were manufactured with a Concept Laser mlab cusing R selective laser melting (SLM) machine (Lichtenfels, Germany). The printing parameters were as follows: laser power $95 \mathrm{~W}$, laser focus point $25 \mu \mathrm{m}$, and scanning speed $800 \mathrm{~mm} \mathrm{~s}^{-1}$. The sample dimensions were $5 \times 5 \times 2 \mathrm{~mm}$. The basic cell dimension was $2 \times 2 \times 2 \mathrm{~mm}$ (Fig. 1). The size of the minimal pore was $330 \mu \mathrm{m}$ and $520 \mu \mathrm{m}$ according to osteogenic cells physiology [45] and previous studies provided on ceramic biomaterials [21,46]. The pore sizes $>300 \mu \mathrm{m}$ are recommended for scaffolds to afford the cells growth and bone tissue regeneration $[24,45]$. The samples for mechanical testing were manufactured according to the ISO13314 standard for compression of porous and cellular metals. The printed scaffolds was heat-treated in a vacuum oven, where they were heated to $820^{\circ} \mathrm{C}$ over a period of $4 \mathrm{~h}$, kept at $820^{\circ} \mathrm{C}$ for 1.5 hours and cooled to $500^{\circ} \mathrm{C}$.

The TPMS structures of primitive (P) - equation 1, I-WP (I) - equation 2 and diamond (D) - equation 3 were modeled by MathMod software [47-49]: 


$$
\begin{aligned}
& \text { P: } \cos (x)+\cos (y)+\cos (z)=0 \\
& \text { D: } \cos (x) \cos (y) \cos (z)-\sin (x) \sin (y) \sin (z)=0 \\
& \mathbf{I}: 2 \cos (x) \cos (y)+2 \cos (x) \cos (z)+2 \cos (y) \cos (z)- \\
& -\cos (2 x)-\cos (2 y)-\cos (2 z)=0
\end{aligned}
$$

The solid surface mesh was modeled and scaled-up (to sizes of $5 \times 5 \times 2 \mathrm{~mm}$ for PEO and for the in vitro experiments, $15 \times 20 \mathrm{~mm}$ cylinders for the mechanical test) by the Materialise Magics software and after was printed on 3D printer in same sizes.

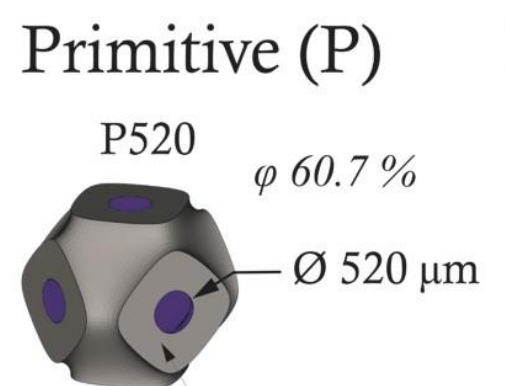

wall size $380 \mu \mathrm{m}$

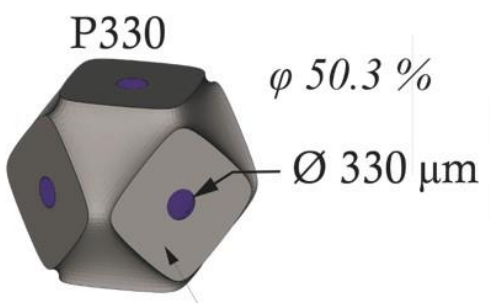

wall size $510 \mu \mathrm{m}$
Diamond (D) D520

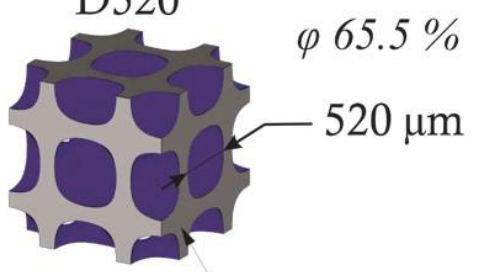

wall size $180 \mu \mathrm{m}$
I-WP (I)

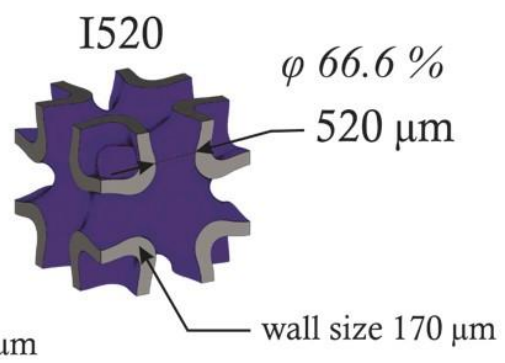

$\mathrm{I} 330$
D330

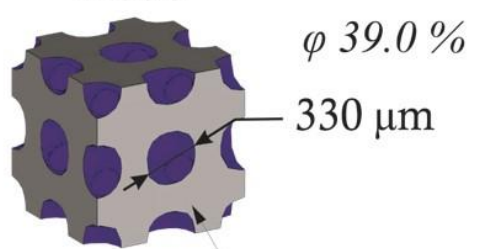

wall size $350 \mu \mathrm{m}$

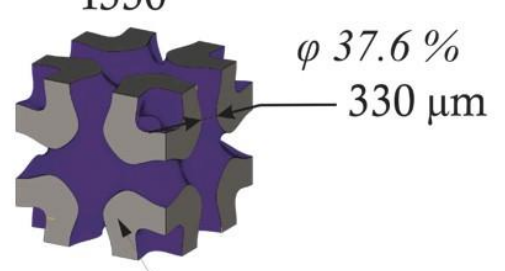

wall size $340 \mu \mathrm{m}$

Figure 1. The basic cells parameters of different samples with TPMS architectures

\subsection{Mechanical testing}

The mechanical properties of the porous scaffolds were measured with an LF TTM 1000 universal testing machine with a $150 \mathrm{kN}$ extensometer (Lohningen, Switzerland). Static compression was applied on five samples for each type of scaffold architecture.

According to the compression test standard for porous and cellular metals (ISO13314 standard), the samples were subjected to deformation with a compression ratio of $10^{-2} \mathrm{~s}^{-1}$, which corresponds to a speed of $1.2 \mathrm{~mm} \mathrm{~min}^{-1}$ for all types of samples with a height of 20 $\mathrm{mm}$. 
The strain-stress diagram of highly porous metals contains a number of features, in particular, the presence of a plateau-like region, where plastic deformation of partitions between the pores occurs. The plateau stress $\sigma_{\mathrm{pl}}$ determines the average stress in the interval of relative deformation of $20-30 \%$ or $20-40 \%$. Other mechanical properties determined in accordance with this standard are related to $\sigma_{\mathrm{pl}}$. The value of $\sigma_{130}$ characterizes the transition from elastic deformation to plastic deformation. The value of $\sigma_{130}$ is calculated as $1.3 \sigma_{\mathrm{pl}}$. The quasi-elastic gradient determines the tangent of a straight line drawn between the points on the diagram that correspond to the stresses $\sigma_{20}$ and $\sigma_{70}$.

\subsection{Characterization of the scaffolds}

The surface morphology was investigated using a JSM-6390 LV microscope (Tokyo, Japan) with an INCA Energy Penta FET X3 energy dispersive microanalysis system (Abingdon, UK) at a $20 \mathrm{kV}$ acceleration voltage. The crystallographic structure investigation of the 3D printed samples were performed by a PanAnalytical X'PertPro diffractometer (Almelo, Niederlande) with special prepared samples with bulk structures and flat surfaces (without pores). This way, a high level of signal noise was avoided. The SLM process and heat treatment parameters were the same as those of the other samples. The sample size for the XRD study was $10 \times 10 \times 2 \mathrm{~mm}$. The detector diffraction hole was $100 \mu \mathrm{m}$, and the anode material was $\mathrm{Cu} / \mathrm{K}$-Alpha $1,54060 \AA$.

\subsection{Plasma electrolytic oxidation (PEO) of scaffolds}

Plasma electrolytic oxidation of the scaffold surface was performed using a DC power supply (PWR 800H, Kikusui, Japan) at a limiting voltage of $300 \mathrm{~V}$ for 5 minutes. Details of the PEO process were described in [50]. All samples were rinsed with distilled water and ultrasonically cleaned in deionized water and 2-propanol for 5 minutes prior to PEO treatment. As the electrolyte, a suspension of $\mathrm{Ag}$ nanoparticles $\left(180 \mathrm{mg} \mathrm{L}^{-1}\right)$ in a solution containing an organic chelating agent (nitrilotriacetic acid), $\mathrm{KH}_{2} \mathrm{PO}_{4}$, and $\mathrm{Ca}(\mathrm{OH})_{2}$ was used 
[51].As the cathode, a titanium mesh was used, and as the anode, the treated scaffold sample was used. To remove any unattached AgNPs, the treated samples were ultrasonically cleaned after the PEO process in 2-propanol for 5 minutes and rinsed with deionized water. Next, the samples were dried in air. Ag nanoparticles were obtained from Nanopure, Poland. The characterization of the AgNPs was described in [51].

\subsection{Characterization of the scaffold surfaces after the PEO process}

The SEM images of the PEO-coated samples were obtained by an FEI Inspect S50B (FEI, Brno, Czech Republic) with the Everhart-Thornley secondary electron detector. To avoid surface charge accumulation in the electron probe, the samples were covered with a thin (30-50 nm) layer of carbon with a vacuum setup VUP-5M (SELMI, Sumy, Ukraine). EDX measurements were carried out using a Zeiss EVO ED15 microscope coupled with an Oxford X-MaxN EDX detector. The structural analysis of the test samples was performed by Raman spectroscopy with a laser source of $532 \mathrm{~nm}$ and power of $10 \mathrm{~mW}$ (Sentera, Bruker, Germany).

The samples, one of each type, were immersed in a resin (Presi, France) to prepare the metallographic cross-sections. After resin drying, the cross-sections were polished using abrasive SiC paper up to 1000 grit. These samples were then sputtered with gold (sputter coater Cressington 108auto) for $90 \mathrm{~s}$. The cross-sections were analyzed using a scanning electron microscope (applied voltage: $15 \mathrm{kV}$, Phenom Pro-X).

\subsection{In vitro experiments}

\subsubsection{Cell culture experiments}

The cells (U2OS cell type) were grown in $75 \mathrm{~cm}^{2}$ cell culture flasks under standard culture conditions of humidified air containing $5 \% \mathrm{CO}_{2}$ at $37^{\circ} \mathrm{C}$ with medium renewal every 2-3 days. Dulbecco's modified Eagle medium/nutrient mixture F-12 (DMEM/F-12) with Lglutamine was used, containing 100 units $\mathrm{mL}^{-1}$ penicillin, $100 \mu \mathrm{g} \mathrm{mL} \mathrm{L}^{-1}$ streptomycin, $2.5 \mu \mathrm{g}$ $\mathrm{mL}^{-1}$ amphotericin B and $10 \%$ fetal bovine serum. The AM scaffolds were sterilized in an 
autoclave, and each scaffold was placed in a separate well of a 24 -well cell culture plate and immersed in DMEM overnight. On the next day, the medium was removed, and the U2OS cells were seeded on each sample and in the wells without samples (as positive control) at a cell density of $10^{4}$ cells per well. Cell adhesion at $24 \mathrm{~h}$ and cell proliferation on the samples were assessed by an Alamar blue colorimetric assay used to measure cell viability. Alamar blue (Invitrogen) was added to each well with an amount equal to $10 \%$ of the medium volume. As a negative control, Alamar blue solution was added to the wells containing only culture medium without cells. As a positive control, Alamar blue solution was added to the wells containing only cells without samples (TCP control). The plates were incubated for $8 \mathrm{~h}$ at $37^{\circ} \mathrm{C}$ in the dark. The medium was then transferred to another 96 -well plate, and the absorbance was measured using a Multiskan FC (Thermo Fisher Scientific, Waltham, MA, USA) plate reader at wavelengths of 570 and $595 \mathrm{~nm}$. The cells were quantified at different time intervals: 1, 3, and 7 days. All experiments were repeated 3 times.

Fluorescence microscopy of the scaffolds after the cell culture experiment was performed. The scaffolds were washed with 1x PBS for 1 minute without shaking. After that, the samples were incubated with 1:35.000 4',6-diamidine-2'-phenylindole dihydrochloride (DAPI, Roche) in PBS for 2 minutes in the dark followed by washing in 1x PBS for 1 minute without shaking. After that, the scaffolds were placed on a glass slide and analyzed with a fluorescence microscope (Axio Imager A1 microscope, Carl Zeiss) in the DAPI channel.

Collagen, which is synthesized by U2OS cells and accumulated on the AM scaffolds, was detected through staining with Sirius Red dye. Staining was performed as follows: on the $7^{\text {th }}$ and $14^{\text {th }}$ days of incubation, the samples were transferred to another 24 -well plate and washed 3 times with ice-cold PBS $\left(4^{\circ} \mathrm{C}\right)$. Then, $1.5 \mathrm{~mL}$ of Bouin's solution was added to each well for 1 hour at room temperature. After the solution was removed, the samples were rinsed with cold tap water and dried in a fume hood overnight. The next day, $1.5 \mathrm{~mL}$ of Sirius Red 
dye was added to the samples for 1 hour and then removed, and each well was washed 4 times with a $0.01 \mathrm{M} \mathrm{HCl}$ solution. One milliliter of a $0.1 \mathrm{M} \mathrm{NaOH}$ solution was added to each well to recover the bound dye. The plate was placed on the shaker for 30 minutes, after which 100 $\mu \mathrm{L}$ of the eluted dye from each well was transferred to a 96-well plate, and the absorbance was measured using a Multiskan FC (Thermo Fisher Scientific, Waltham, MA, USA) plate reader at a wavelength of $550 \mathrm{~nm}$.

\subsubsection{Bacterial assay}

S. aureus (strain B 918) obtained from the National Collection of Microorganisms (D.K. Zabolotny Institute of Microbiology and Virology, Kiev, Ukraine) were cultivated on nutrient agar for $24 \mathrm{~h}$. The suspensions of the overnight strains were mixed with nutrient broth, and the final concentration of microorganisms was adjusted to $10^{5} \mathrm{CFU}$ (colony forming unit) using a McFarland standard. Sterile 3D samples were placed horizontally into plastic 24-well plates containing $2.0 \mathrm{~mL}$ of bacterial suspension. All test samples, negative (media) and positive (bacteria) controls were incubated at $37^{\circ} \mathrm{C}$ for $24 \mathrm{~h}$. Ten-microliter aliquots from each well were pipetted onto the nutrient agar for $2 \mathrm{~h}, 4 \mathrm{~h}, 6 \mathrm{~h}$ and $24 \mathrm{~h}$ using the streak plate technique. The colony forming units (CFU) were calculated by counting the visible colonies and expressed as log units. All measurements were performed in triplicate.

\section{Results and discussion}

\subsection{D scaffolds characterization}

The microstructures of the printed Ti6Al4V scaffolds after heat treatment showed a beta phase ( $\beta$-phase) diffusion in the alpha phase ( $\alpha$-phase) matrix (Fig. 2a) [52]. The segregation of alloy components is observed (Fig. 2b-c, Tab. 1). The vanadium segregation takes place by $\alpha$ stabilizer aluminum depletion [53], which has higher diffusion ability. The secondary total $\alpha$-phase transition did not occur because there was no subsequent aging heat treatment $[52,54]$. There was no significant change in the chemical composition at different 
measurement points of the samples analyzed by EDX, and we concluded that the composition was close to homogenous. The compositional SEM images and tables of EDX data are given in supplementary data.

The XRD studies confirmed that the samples exhibited a binary structure containing two Ti phases (Fig. 3). The main phase was $\alpha-\operatorname{Ti}$ (hcp) with lattice parameters $a=2.939 \AA, b=$ $2.939 \AA, c=4.641 \AA, \alpha=90.000^{\circ}, \beta=90.000^{\circ}$, and $\gamma=120.000^{\circ}$. The secondary phase was $\beta$-Ti (bcc) with lattice parameters $a=2.906 \AA, b=2.906 \AA, c=2.906 \AA, \alpha=60.000^{\circ} \beta=$ $60.000^{\circ}$, and $\gamma=60.000^{\circ}$.
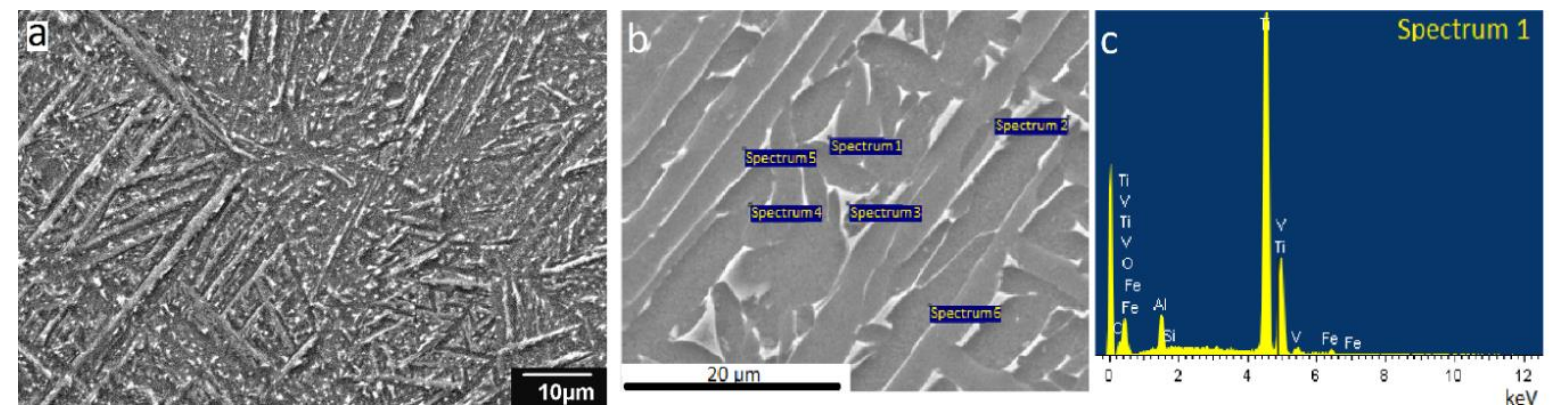

Figure 2. The microstructure of the exemplary scaffold $(a, b)$ as well as the exemplary EDX spectra (c)

Table 1. The EDX analysis results of the scaffold in points marked in Fig $\mathbf{2 b}$, wt.\%

\begin{tabular}{lllll}
\hline Spectrum & $\mathrm{Al}$ & $\mathrm{Ti}$ & $\mathrm{V}$ & Sum \\
\hline Spectrum 1 & 4.3 & 84.9 & 10.9 & 100.0 \\
Spectrum 2 & 6.1 & 89.2 & 4.7 & 100.0 \\
Spectrum 3 & 6.9 & 90.1 & 3.1 & 100.0 \\
Spectrum 4 & 6.5 & 91.3 & 2.2 & 100.0 \\
Spectrum 5 & 6.9 & 91.1 & 2.0 & 100.0 \\
Spectrum 6 & 6.9 & 91.9 & 1.3 & 100.0 \\
\hline Average & 6.3 & 89.7 & 4.0 & 100.0
\end{tabular}




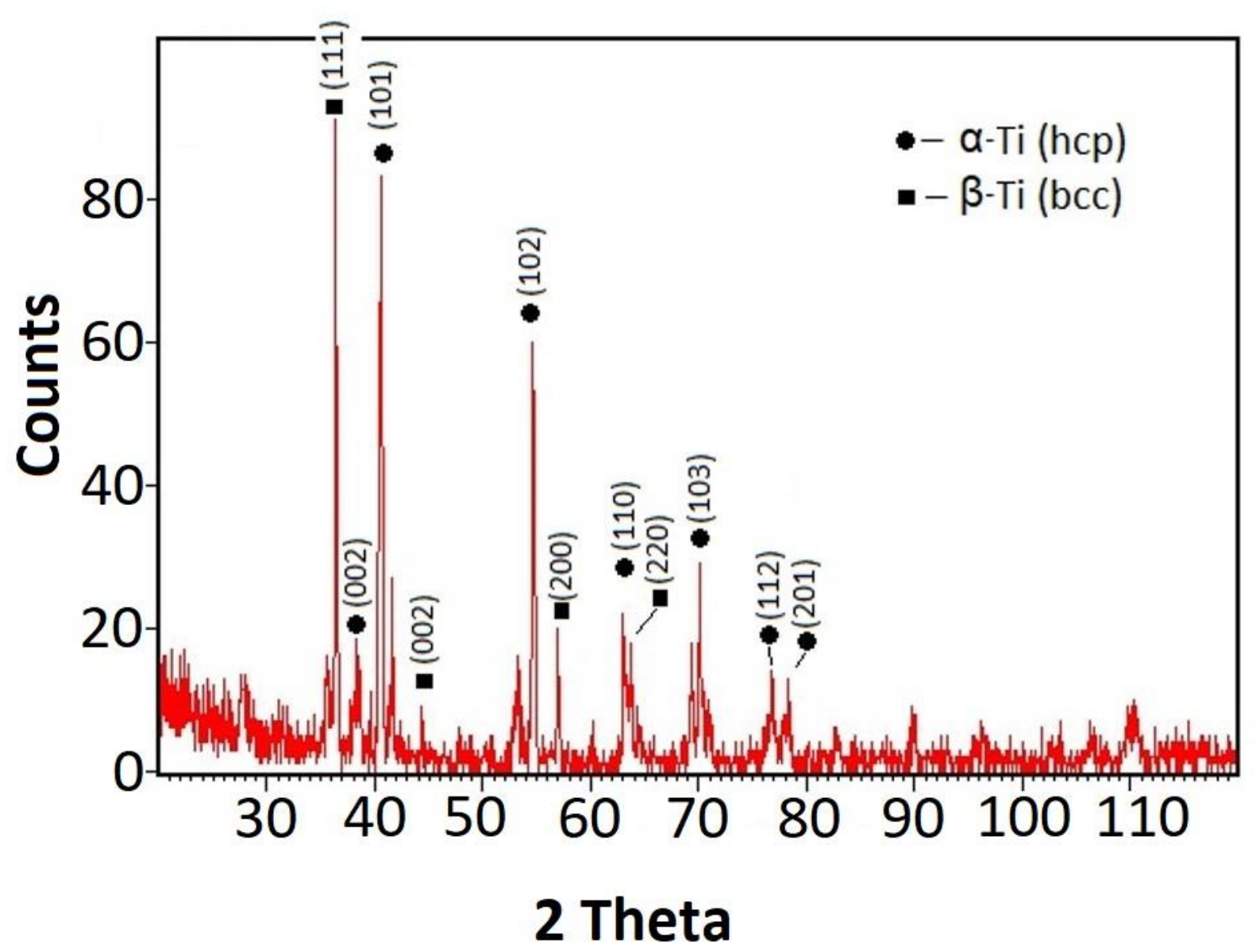

Figure 3. The XRD pattern of the Rematitan ${ }^{\circledR C L}$ titanium alloy after the SLM process and heat treatment

The deformation curves obtained after conducting static compression tests were used to determine various mechanical properties of the material, such as plateau stress, quasielastic gradient and other characteristics. The stress-strain curves of the scaffolds were characterized by subsequent stages of deformation as well as features including a linear increase in stress with strain, a relatively long plateau region with stress oscillating, and finally a region of rapid increase in stress (Fig. 4). The peaks and troughs in the stress-strain curves (Fig. 4) were caused by the formation of shear lines and the accumulation of stresses after the load was transferred to the following layer or unit cell with a minimal surface. The stress-strain curves essentially were the same in all cases. The most elastic scaffold was the 
I330 architecture, despite a thinner wall size; however, the P330 architecture had the lowest elasticity among scaffolds with $330 \mu \mathrm{m}$ pores (Fig. 5a). In general, scaffolds with larger pore sizes demonstrated poorer mechanical properties. Sample D520 showed the lowest elasticity and the lowest compressive strength among the scaffolds. Architecture I330 demonstrated the best compressive strength, despite its thinner wall size (Fig. 5b). There is no direct correlation between wall thickness and structures' mechanical properties, for example the wall thickness of P330 is higher than $\mathrm{I} 330$ or D330 $(510 \mu \mathrm{m}$ vs 340 and $350 \mu \mathrm{m})$, at the same time the compressive strength lower for $\sim 1.5$ times. The scaffold's architecture type has an essential role in samples mechanical properties.
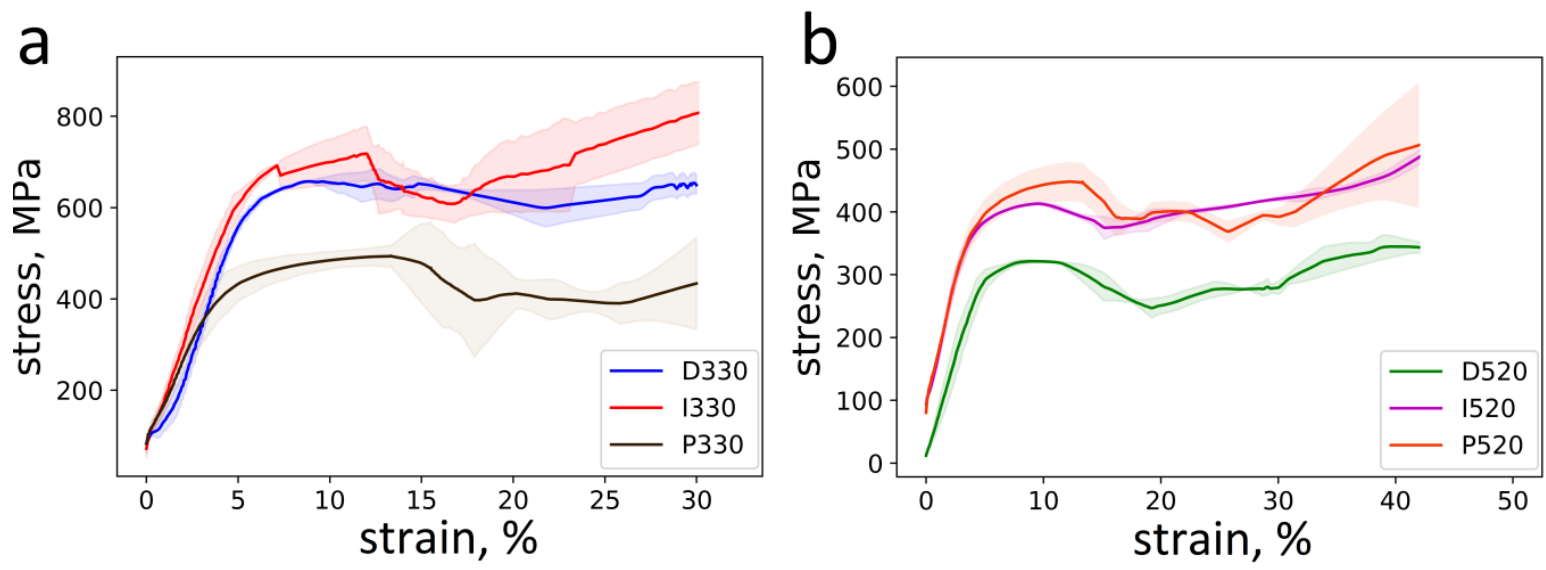

Figure 4. The stress-strain curves for Primitive, I-WP, Diamond structures with different minimal diameters of pores $(\mathrm{a}-330 \mu \mathrm{m} ; \mathrm{b}-520 \mu \mathrm{m})$ 

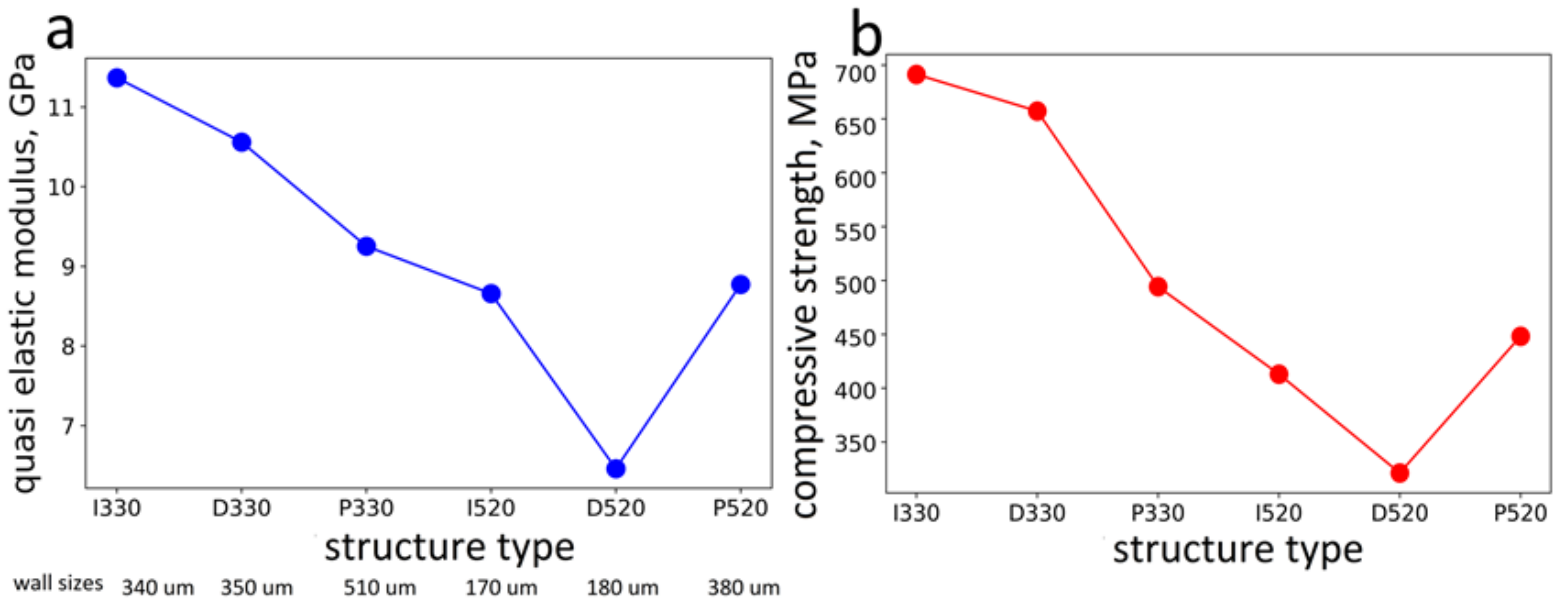

Figure 5. Derived mechanical characteristics of Primitive, I-WP, Diamond structures with different minimal diameters of pores ( $a$ - quasi elastic modulus; $b$ - compressive strength $\sigma_{130}$

The destruction behavior of the porous scaffolds are presented in Fig 6. The P330 and P520 samples were deformed in the form of a barrel, and in the P330 samples cell destruction was observed along a diagonal of $\sim 45$ degrees. In case of diagonal distruction the average height of the samples after test was different, pore displacement and compaction were observed (Fig. 6 a, b, c). The D330 and D520 samples were not subject to severe destruction; however, a shift of $\sim 45$ degrees and compaction of the layers were also observed (Fig. 6 a, d). However, this did not lead to crack propagation. D330 revealed a developing crack and defects, which ultimately led to the complete destruction of the sample at $\sim 45$ degrees (Fig. 6a). A complete displacement of the cells with respect to each other was observed for I520. In this case, the weak parts of the geometry are the bonds between two vertical and horizontal supports of the unit cell. These cracks occurred in the uprights on the periphery of the sample and propagated to the center through the vertical uprights and further along the entire perimeter of the sample (Fig.6 e). 


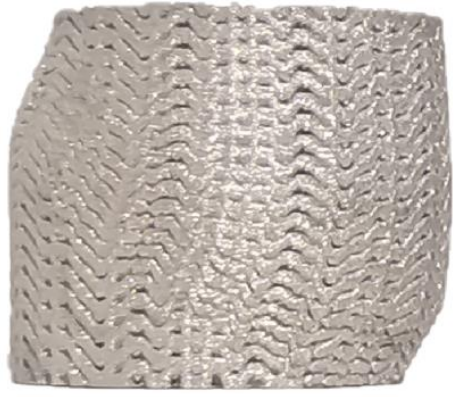

D330

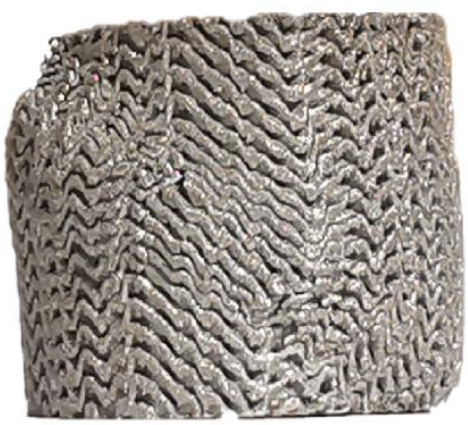

D520

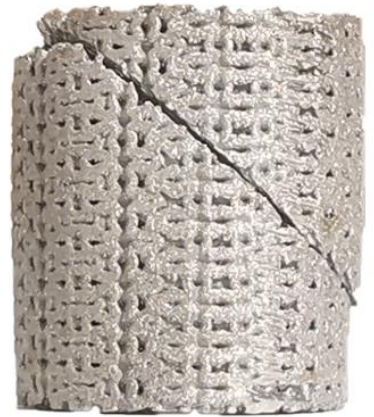

$\mathrm{I} 330$

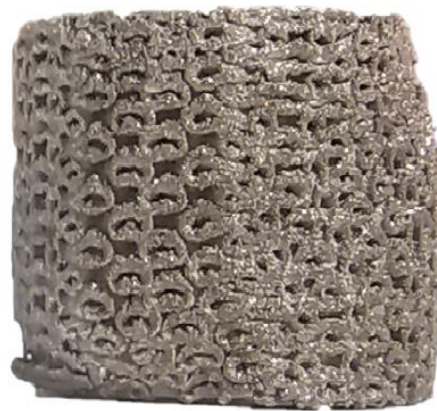

I520

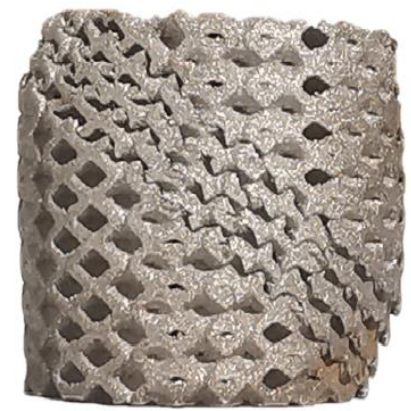

P330

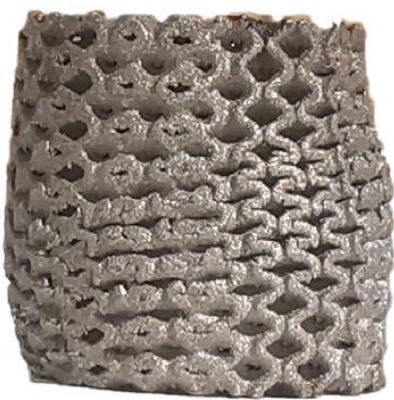

P520

Figure 6. The destruction behavior of porous scaffolds with different architecture

According to obtained results of mechanical tests the scaffolds with TPMS structure destroy by same way as were shown previously in $[15,55]$. The scaffolds, obtained by us, have higher mechanical properties for $20 \%$ in average, than the scaffolds developed by [15]. It could be explained by difference in printing regimes and thermal treatment after printing process, that was not been done.

Printing thin-walled structures with minimal surface area is a difficult task. Due to the high temperature gradient during the SLM process, martensitic structure and surface spheroidization occurred. The elemental distribution was close to homogenous. However, we observed segregation of vanadium, where the $\beta$-phase diffused into the $\alpha$-phase matrix. The mechanical properties of human bone are quite relative due to a number of parameters, such as age, sex, depth of test area, anatomical uniqueness, etc. Moreover, it is impossible to develop materials with low elasticity and high strength because both parameters are positively 
correlated with each other. The obtained TPMS scaffolds exhibited a quasi-elastic modulus between 6.4-11.4 GPa, which matches that of the trabecular bone (10.4-14.8 GPa) and is close to the elastic modulus of the cortical bone (18.6-20.7 GPa) [5-7]. The compressive strength of the produced TPMS scaffolds deviated between 321 and $691 \mathrm{MPa}$, which was higher than that of human cortical bone (95-165 MPa) [56]. Taking into account the principal role of the elastic module in stress-shielding syndrome, new TPMS scaffolds offer great potential as bone-grafting materials.

\subsection{Plasma electrolytic oxidation of the 3D scaffolds}

The 3D printed TPMS scaffolds had rough surfaces caused by spheritic drops of melted Ti powder. This is typical in TPMS structures printed by the SLM method because several effects occur during the process. These are 1) partial melting due to curved struts of varying angles and 2) thermal diffusion due to a substantial temperature gradient [55]. The SEM images of the PEO-coated scaffolds with different architectures are shown in Fig. 7. The scaffold surface was well-developed with the characteristic porosity of PEO-formed oxides. The differences in the coating morphology can be explained by changes in the surface gradient, which provides uneven current density and distribution of discharges [57], resulting in different coating thicknesses (Figs. 7b, e, h). Cracks could be observed in the coating after the addition of the silver nanoparticles regardless of the scaffold type. These cracks occurred due to the effect of thermal stresses caused by the rapid solidification of molten oxides by electrolytes with higher conductivity [57,58].

The silver nanoparticles were uniformly distributed on the coating surface. The nanoparticles had a crystallite form, probably due to aggregation with sizes between 100-200 nm (Fig. 7 1) [50]. 

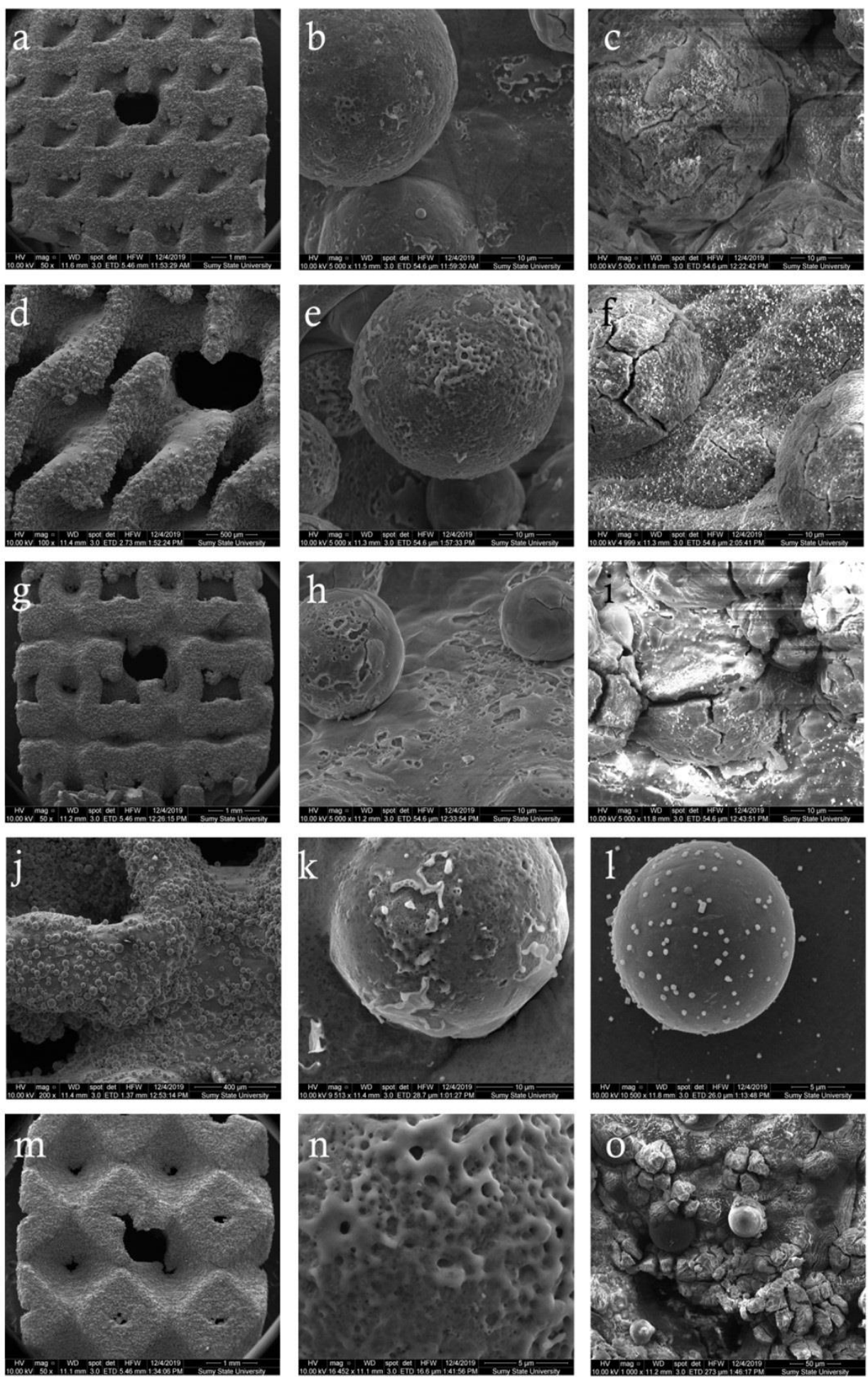

Figure 7. The SEM images of scaffolds after the PEO treatment; a, b) D330-PEO; c) D330PEO-Ag; d, e) D520-PEO; f) D520-PEO-Ag; g, h) I330-PEO; i) I330- PEO-Ag; j, k) I520PEO; 1) I520- PEO-Ag; m, n) P330-PEO; o) P330-PEO-Ag 
The semiquantitative chemical composition of the scaffolds after PEO processing is shown in Tab. 2. The addition of silver nanoparticles to the electrolyte decreased the oxygen, titanium, aluminum, and vanadium concentrations and increased the chlorine content. The decrease in oxygen content was also indirectly proven by Raman analysis (Fig. 8.). The presence of chlorine was related to the Ag nanoparticle preparation method [50]. The concentration of phosphor decreased after silver nanoparticle incorporation; however, the calcium content fluctuated in an unpredictable manner. In general, scaffolds with the "I-WP" architecture exhibited an elemental distribution similar to the "diamond" structure, and the "primitive" architecture showed a different distribution in the case of silver nanoparticle addition.

Table 2. The semi-quantitative EDX analysis of scaffolds after the PEO process, wt.\%

\begin{tabular}{lcccccccccc}
\hline Sample & $\mathrm{O}$ & $\mathrm{Al}$ & $\mathrm{P}$ & $\mathrm{Cl}$ & $\mathrm{Ca}$ & $\mathrm{Ti}$ & $\mathrm{V}$ & $\mathrm{Ag}$ & $\mathrm{Ca} / \mathrm{P}$ ratio & Sum \\
\hline P330-PEO & 37.9 & 3.1 & 2.7 & 0.1 & 0.4 & 53.6 & 2.2 & - & 0.2 & 100.0 \\
P330-PEO-Ag & 34.7 & 2.1 & 2.2 & 4.2 & 1.6 & 41.7 & 1.8 & 11.7 & 0.7 & 100.0 \\
D330-PEO & 37.9 & 3.1 & 2.7 & 0.1 & 0.4 & 53.6 & 2.2 & - & 0.2 & 100.0 \\
D330-PEO-Ag & 34.0 & 2.7 & 1.4 & 3.9 & - & 48.8 & 2.3 & 6.8 & - & 100.0 \\
I330-PEO & 39.2 & 2.2 & 3.7 & 0.2 & 2.6 & 50.7 & 1.5 & - & 0.7 & 100.0 \\
I330-PEO-Ag & 37.2 & 3.2 & 2.2 & 1.0 & 1.0 & 46.8 & 2.4 & 6.1 & 0.5 & 100.0 \\
\hline
\end{tabular}

The Raman spectra of the coatings on the scaffolds are presented in Fig. 8. Titanium dioxide has three polymorphic phases: rutile, anatase (tetragonal), and brookite (orthorhombic). The Raman-active fundamental modes for rutile $\left(\mathrm{TiO}_{2}\right)$ are $143 \mathrm{~cm}^{-1},\left(\mathrm{~B}_{1 \mathrm{~g}}\right)$, $447 \mathrm{~cm}^{-1}\left(\mathrm{E}_{\mathrm{g}}\right), 612 \mathrm{~cm}^{-1}\left(\mathrm{~A}_{1 \mathrm{~g}}\right)$, and $826 \mathrm{~cm}^{-1}\left(\mathrm{~B}_{2 \mathrm{~g}}\right)$ [59]. However, the polymorph phase of $\mathrm{TiO}_{2}$ brookite has a complex of 17 characteristic bands at 127, 153, 194, 247, 412, $640 \mathrm{~cm}^{-1}$ $\left(\mathrm{A}_{1 \mathrm{~g}}\right), 133,159,215,320,415,502 \mathrm{~cm}^{-1}\left(\mathrm{~B}_{1 \mathrm{~g}}\right), 366,395,463,584 \mathrm{~cm}^{-1}\left(\mathrm{~B}_{2 \mathrm{~g}}\right)$ and $452 \mathrm{~cm}^{-1}$ $\left(\mathrm{B}_{3 \mathrm{~g}}\right)[60,61]$. The strongest band for brookite is $153 \mathrm{~cm}^{-1}[60]$. Anatase has a very strong band 
at $144 \mathrm{~cm}^{-1}$ and six Raman-active fundamentals: $144 \mathrm{~cm}^{-1}, 197 \mathrm{~cm}^{-1}\left(\mathrm{E}_{\mathrm{g}}\right), 400 \mathrm{~cm}^{-1}\left(\mathrm{~B}_{1 \mathrm{~g}}\right), 507$ $\mathrm{cm}^{-1}\left(\mathrm{~A}_{1 \mathrm{~g}}\right), 519 \mathrm{~cm}^{-1}, 640 \mathrm{~cm}^{-1}\left(\mathrm{E}_{\mathrm{g}}\right)[60,62]$. The Raman spectra of the scaffolds showed a similar pattern with a broad strong band at $140-165 \mathrm{~cm}^{-1}$ and broad Raman group bands with lower intensities, 380-420 $\mathrm{cm}^{-1}$, 500-535 $\mathrm{cm}^{-1}, 575-650 \mathrm{~cm}^{-1}$. By analyzing the Raman spectra, we assumed that the phase compositions of the coatings were a mixture of brookite, anatase and rutile phases. The addition of silver nanoparticles shifted the maximum, which is attributed to brookite, from $\sim 154 \mathrm{~cm}^{-1}$ to $144 \mathrm{~cm}^{-1}$, the strongest band of anatase, and to 95 , 143, $190 \mathrm{~cm}^{-1}$ related to silver chloride [63]. The insignificant influence of the silver nanoparticles on the resulting spectra was reasonable, as the silver content based on the elemental composition was low, and there were only minor changes of the intensities in the spectra of the silver-added sample. The lack of the main bands of silver oxide at 390,540, and $560 \mathrm{~cm}^{-1}$ suggested its absence [64]; however, the presence of silver oxide was shown in our previous paper [65]. The calcium and phosphorus compound bands were not visible in the Raman spectra. We can conclude that these compounds in the form of apatites were present in an amorphous form [66]. 

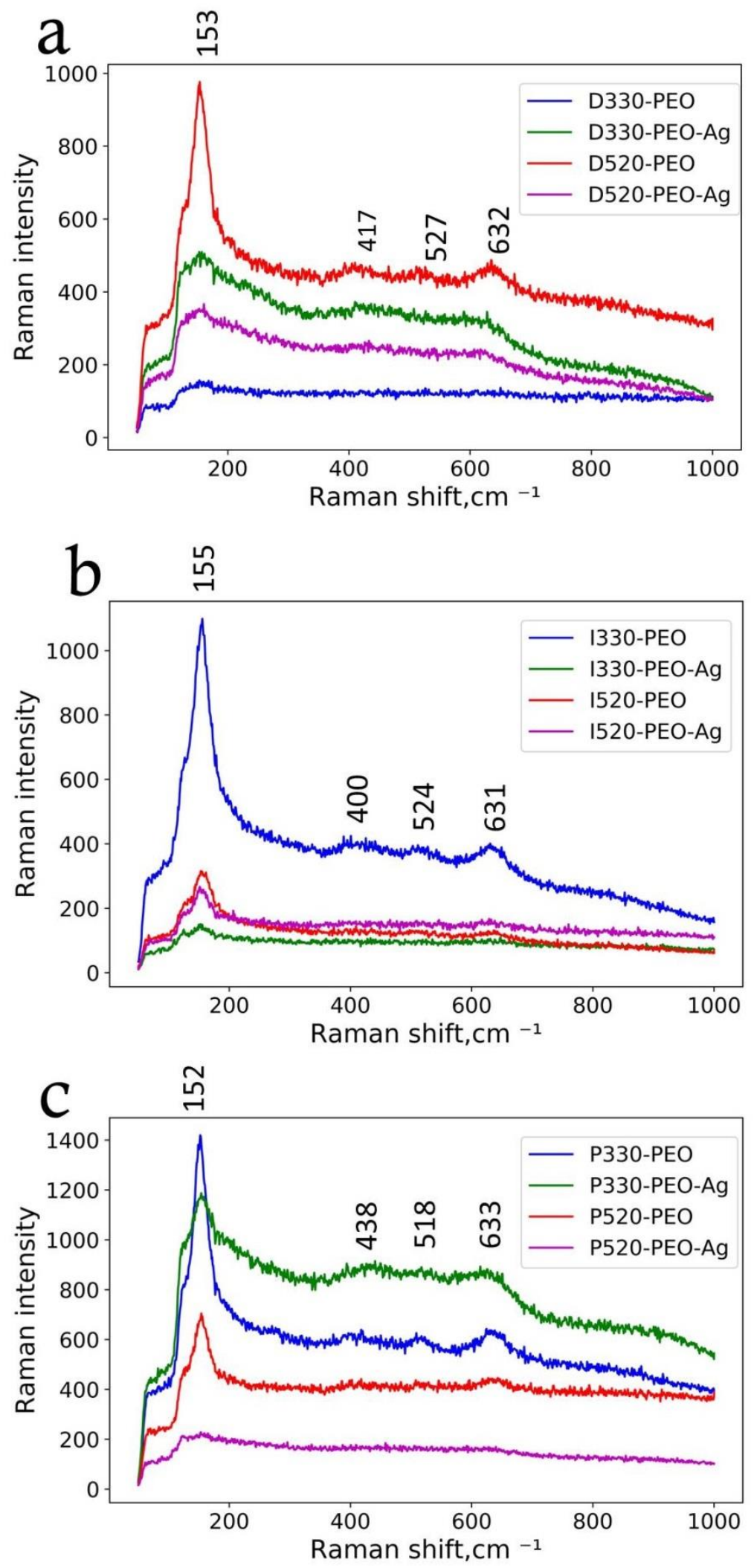

Figure 8. The Raman spectra of scaffolds after the PEO process; a) Diamond; b) I-WP; c)

Primitive 
The uniform oxide coating was successfully formed along the substrate border and mostly uninterrupted (Figs. 9 and 10). This is a great benefit of the PEO process because it allows forming oxide layers on samples with difficult shapes, such as dental implants [67].

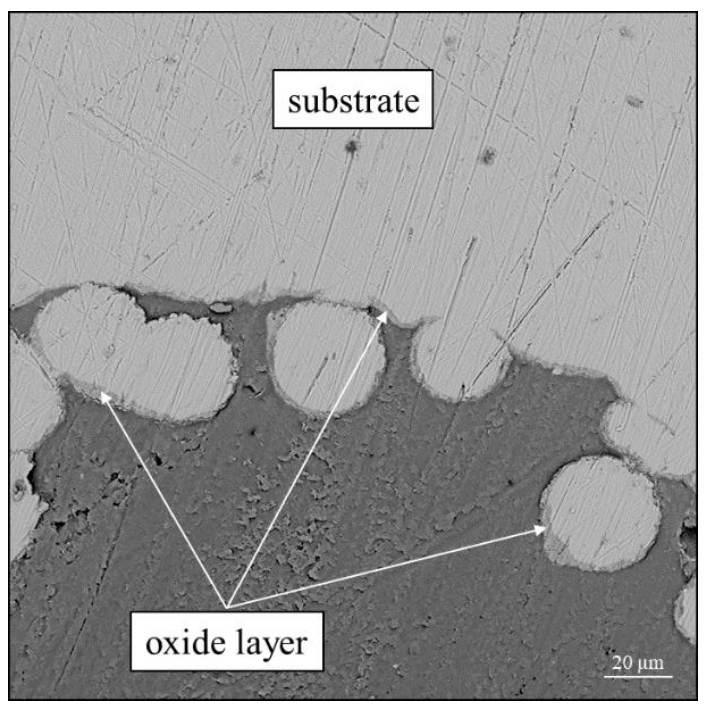

Figure 9. The SEM image of I330-PEO-Ag sample cross section

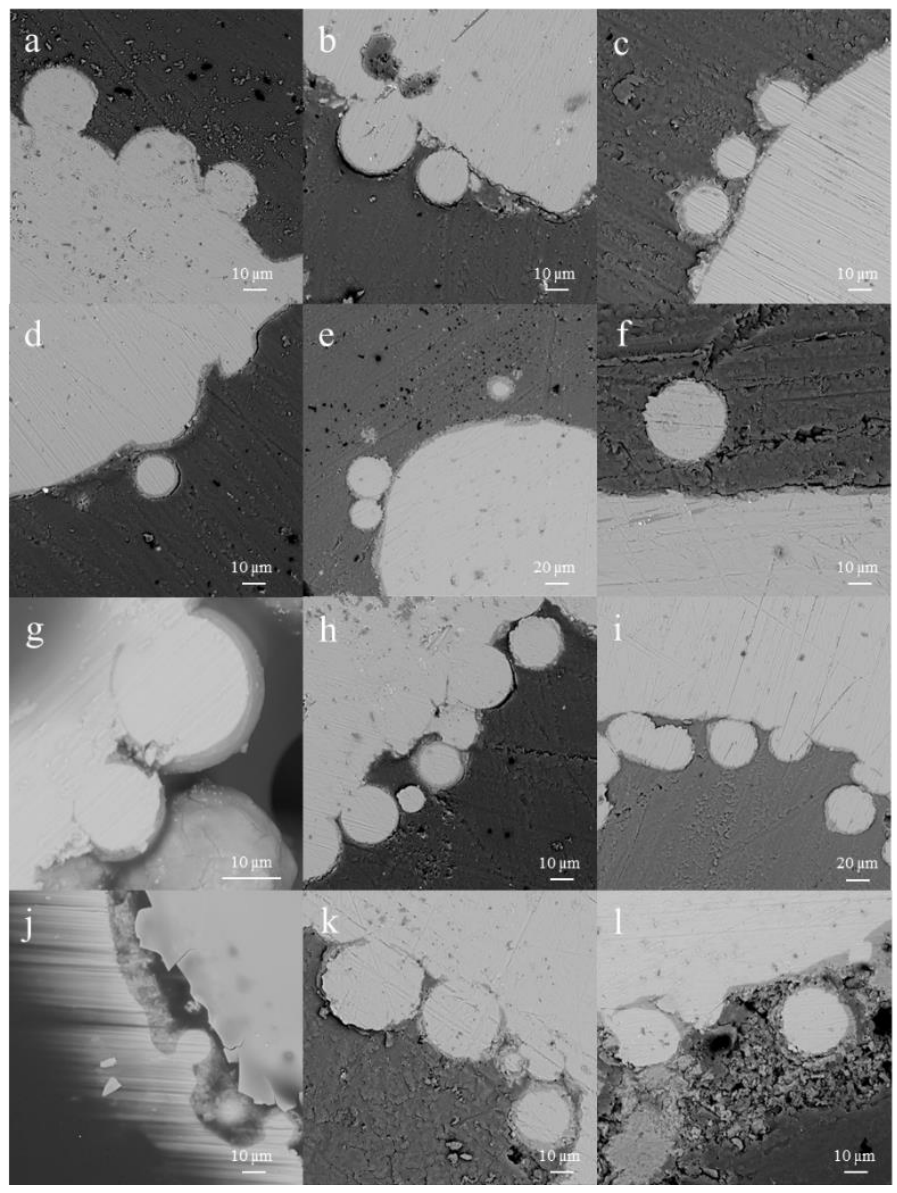


Figure 10. The SEM images of cross-sections of scaffolds after the PEO process; a) D330-PEO; b) D520-PEO; c) I330-PEO; d) I520-PEO; e) P330-PEO; f) P520-PEO; g) D330-PEO-Ag; h) D520PEO-Ag; i) I330-PEO-Ag; j) I520-PEO-Ag; k) P330-PEO-Ag l) P520-PEO-Ag

\subsection{In vitro biocompatibility and antibacterial properties}

There was no significant difference in U2OS cell adhesion on day 1: the as-cast and PEO-modified samples showed the same resazurin reduction, and the AgNPs in the PEO layer did not affect the cell adhesion. The as-cast TPMS samples provided appropriate conditions for cell proliferation within 7 days of cultivation: the resazurin reduction increased to $82.5 \pm 4.8 \%$ (Fig. 11, 1). It should be noted that the pore size of the as-cast TPMS scaffolds did not influence the cell adhesion and proliferation. The PEO modification leads to a pore size reduction that could influence the cell migration inside the pores. We observed a slight reduction in the cell proliferation on day 7 for the D330-PEO and I330-PEO samples. On the other hand, the 520 pore sizes maintained the cell proliferation from the $1^{\text {st }}$ to $7^{\text {th }}$ day of the experiment compared to the 320 pore sizes (Fig. 11, 1a, 1b). Silver nanoparticles had no influence on the cell adhesion and proliferation from the $1^{\text {st }}$ to $3^{\text {rd }}$ day of the experiment. The proliferation rate of U2OS decreased compared to that of the non-Ag groups on day 7, possibly due to silver release from the ceramic coating. Samples with 520 pore size showed a significant reduction in the cell viability due to high contact surface area and possible faster silver ion release. Despite cell proliferation inhibition, the silver-incorporated surface was nontoxic and could be used for orthopedic and dental implant modification.

Fluorescent DAPI staining (Fig 11, 2) demonstrated a high cell number in the as-cast scaffolds and the PEO-coated samples and a significant reduction in the number of U2OS cells in the Ag-incorporated groups. The fluorescent images revealed the cell migration and their preferred location within the pores, demonstrating the osteoconductive abilities of the TPMS structures. DAPI staining revealed no difference between cell migration in the 
diamond, primitive and I-WP architectures but a significant influence of $\mathrm{Ag}$ on the cell proliferation at the final time point.
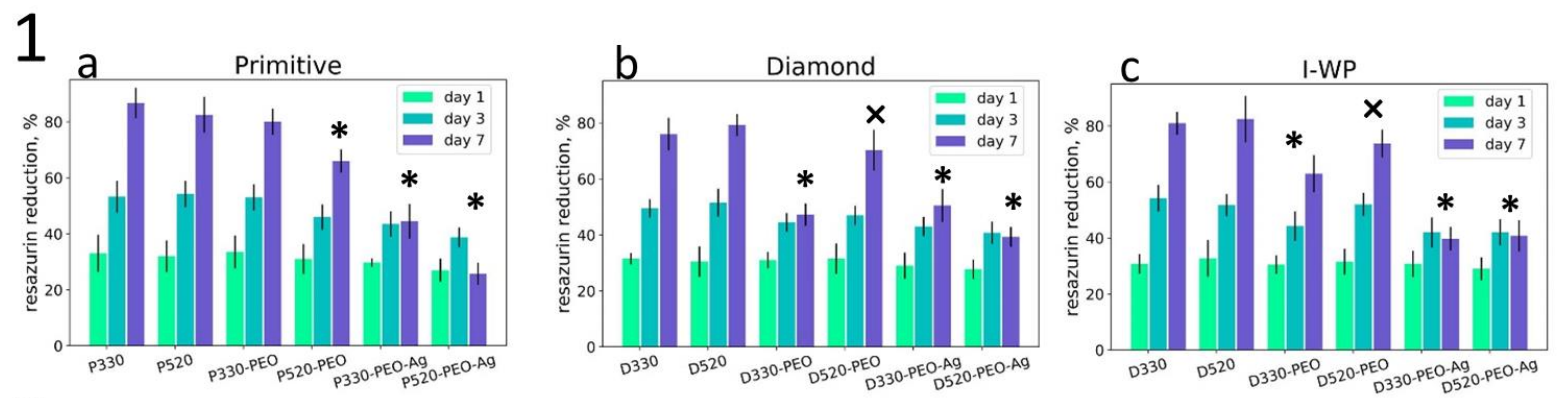

2

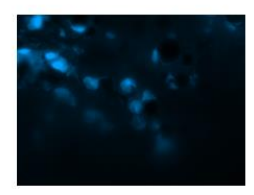

P330

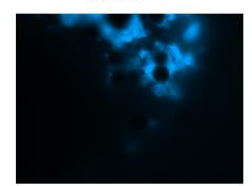

D330

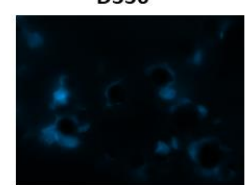

1330

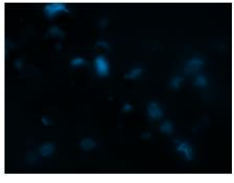

P520

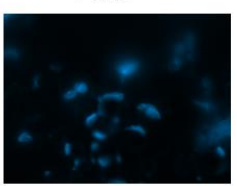

D520

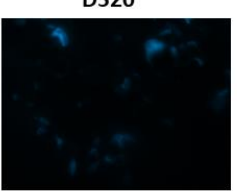

1520

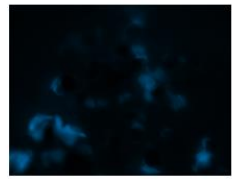

P330-PEO

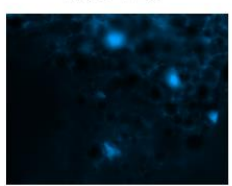

D330-PEO

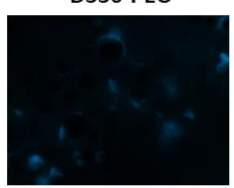

1330-PEO

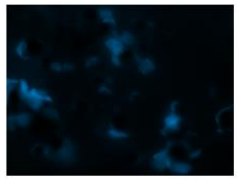

P520-PEO

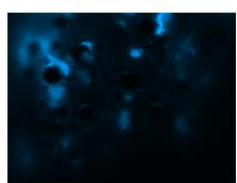

D520-PEO

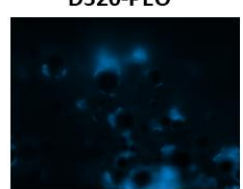

I520-PEO

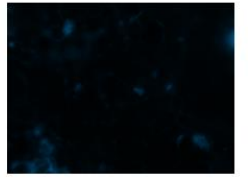

P330-PEO-Ag

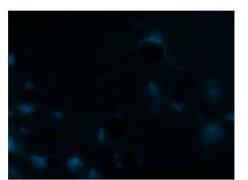

D330-PEO-Ag

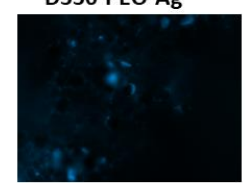

I330-PEO-Ag

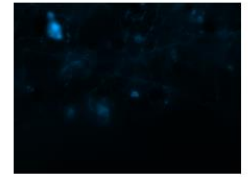

P520-PEO-Ag

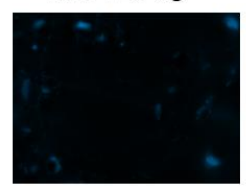

D520-PEO-Ag

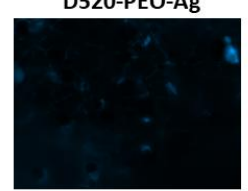

I520-PEO-Ag
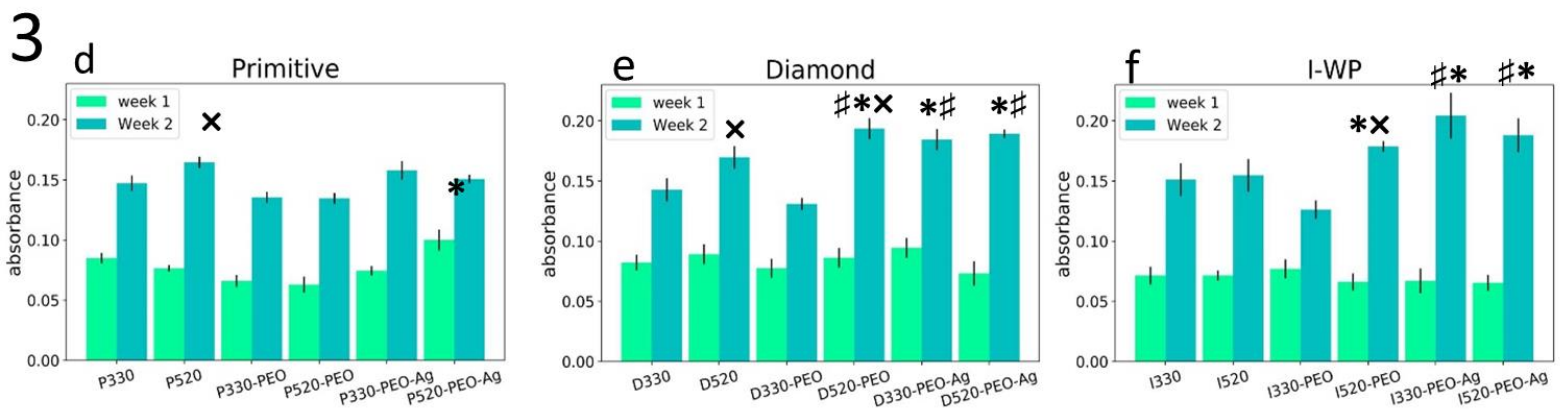

Figure 11. Resazurin reduction assay demonstrating U2OS adhesion on day one and proliferation in 3 and 7 days (1) with fluorescent DAPI staining in day 7 (2) and the absorbance intensity of Sirius red demonstrating collagen production rate in 1 and 2 weeks after cell seeding (3)

* - significant difference with non-treated samples $(\mathrm{p} \leq 0.05) ; \mathbf{x}$ - significant difference between 330 and 520 pore sized samples $(\mathrm{p} \leq 0.05)$ 
Collagen production is one of the significant signs of osteoblast cell line activity. As shown in Fig. 11 (3), an increase in Sirius red absorbance demonstrated significant growth after two weeks of U2OS cultivation in the PEO-coated samples (both with and without AgNPs) on the diamond and I-WP architecture (Fig. 11, 3d, 3e). The silver-incorporated surface did not influence the collagen production. The collagen production at week 2 depended mainly on the pore size, and the 520 sample provided a better environment for cell penetration, as indicated by a significant increase in the Sirius red absorbance. To summarize the results of the cell proliferation experiment and collagen assay, the calcium-phosphate ceramic coating and the pore size were the main factors influencing the U2OS proliferation and activity. The diamond and I-WP architecture resulted in a significantly higher collagen production than the other samples but had no influence on the cell proliferation.

A 24-hour experiment demonstrated a significant reduction in the bacterial adhesion, which could be observed as early as 2 hours after $S$. aureus coculturing on silver-incorporated samples. The bacterial count ranged between 2.0 and 4.69 Log 10 CFU in 4 and 6 hours. At 24 hours, the bacteria slightly proliferated, but their proliferation was still significantly lower than that of the nontreated and PEO-coated samples. The scaffold architecture had no effect on the bacterial survival rate (Fig. 12).

Despite the complex morphology of the TPMS scaffold, PEO allows for the formation of a uniform coating with calcium-phosphate ceramic, which could induce additional stimuli for osteoblast cell adhesion and proliferation [68]. The addition of AgNPs to the PEO solution had a notable influence on the coating microstructure.. Our studies prove that there was an antibacterial effect of silver in the PEO layer to prevent postoperative bacterial complications [65]. There have been some reports about the cytotoxic effect of AgNPs, but our data demonstrated the safety of the PEO-Ag layer during a 7-day osteoblast cell culture 
experiment. Balanced AgNP concentrations coupled with low silver release could prevent cytotoxic effects during long-term implant application.
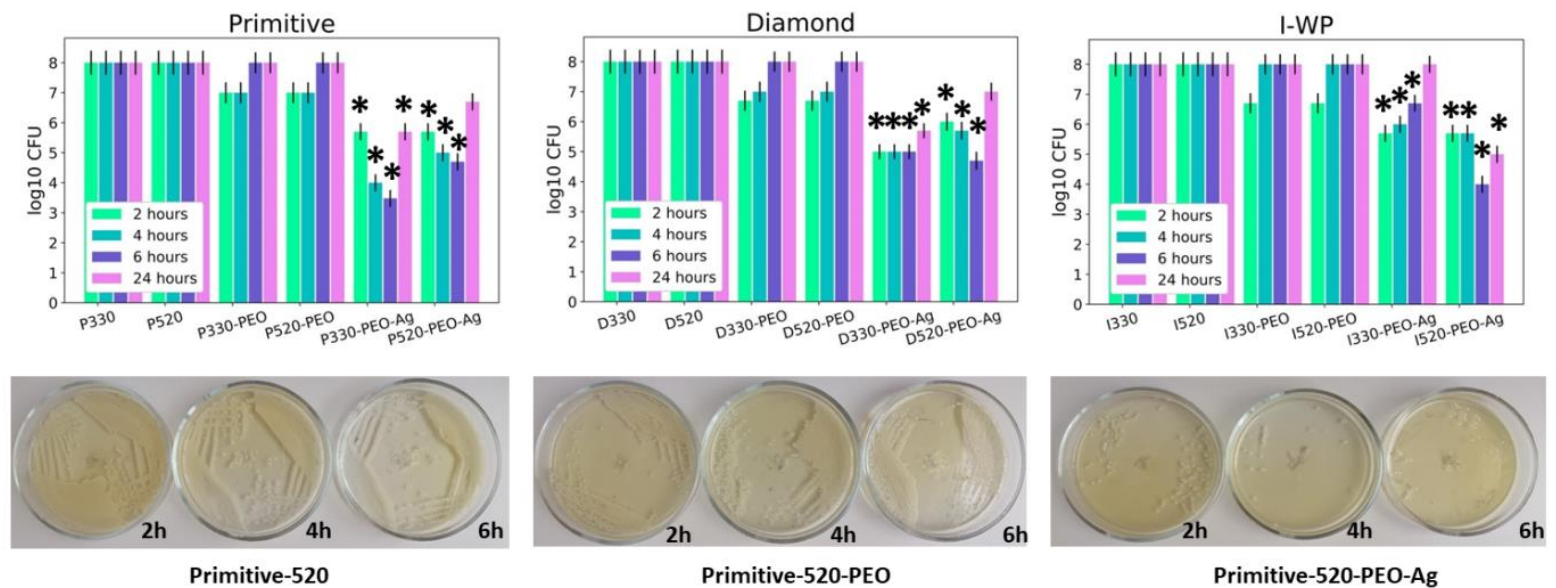

Figure 12. Bacteria survival rate in different time-points (2, 4, 6 and 24 hours) after $S$. aureus co-cultivation calculated in Log10 CFU (upper row) and visible colonies of S. aureus in Petri dishes for as-cast, PEO-coated and Ag-doped groups (low row)

* - significant difference with non-treated samples $(\mathrm{p} \leq 0.05)$

The mechanotransduction principles are the basis for most theories that correlate pore architecture and bone growth [24]. It is known that pore shape and size accompanied with the surface chemistry are the main factors influencing osteoblast cell growth [69,70]. Firstly, after scaffold-to-tissue interaction, blood and interstitial fluid accumulate inside the pores [71]. At this stage, the surface wettability and chemical composition play crucial roles [72]. Some studies have suggested that PEO-coated implants are a suitable surface for protein adsorption, and PEO-TPMS scaffolds are advantageous at this stage [73]. The second stage is the primary attachment of cells by focal adhesion on the surface [74] and consequent cell network generation due to contractile forces [75]. The PEO coating provides additional stimuli for cell attachment due to its free functional groups, such as $-\mathrm{OH},-\mathrm{COOH}$ and calcium-phosphates [65]. Our experiment showed that the pore size played an important role in cell attachment $520 \mu \mathrm{m}$ pores provided more sites for cell attachment than $330 \mu \mathrm{m}$ pores. Additionally, the 
PEO process leads to a decrease in the pore dimensions, and TPMS scaffolds with large pores have significant advantages for clinical application. The next stage, cell proliferation, is a complex process requiring osteoinductive stimuli for appropriate bone tissue formation. A higher rate of osteoblast proliferation was observed for structures with larger pore sizes $[45,76]$. However, larger pores might not be beneficial in the stage of primary cell attachment due to the high rate of permeability as a result of high fluid flow and mass transport. The last stage of bone regeneration is coupled with the previous stage of angiogenesis, and mature bone formation occurs with further remodeling. We did not observe this stage in our experiment, but sufficient osteoblast cell attachment and proliferation could provide appropriate conditions in vivo for new tissue development. The collagen production rate was measured by assessing the osteoblast cell activity. A high rate of collagen production was observed for both the D520 and I520 architectures. PEO coatings containing calcium and phosphate were found to increase the cell activity, which in turn resulted in a higher rate of collagen production. This may be due to better cell adhesion and bioactive media conducive to cell growth. Although the silver nanoparticles did not stimulate collagen production, they played an important role in controlling bacterial contamination. Fluorescent DAPI staining confirmed the osteoconductive properties of TPMS structures that allow primary cell fixation inside pores with further extracellular matrix deposition. Additional calcium-phosphate coating could provide stimuli for osteogenic cell adhesion and proliferation. Bacterial elimination in Ag-incorporated samples may allow cells to efficiently adhere to substrates with reduced infection complications in real clinical situations.

We believe that osteoblast cell activity primarily depends on the permeability coefficient (TPMS structure type) followed by the pore size. It has been shown that collagen production is inversely proportional to the permeability coefficient [15].

\section{Conclusions}


3D scaffolds with three types of triply periodic minimal surfaces and different minimal pore diameters and porosities were additively manufactured and functionalized via plasma electrolytic oxidation with silver nanoparticles. The mechanical parameters of the newly produced scaffolds matched the biomechanical properties of natural bone, which might eliminate the risk of premature implant failure caused by the stress shielding effect. The bioactive ceramic coating did not significantly affect the cell proliferation but stimulated the collagen production, an important parameter for new bone formation. The silver nanoparticles incorporated into the ceramic oxide coating demonstrated a high rate of antibacterial activity against gram-positive and gram-negative bacteria and did not exert a significant effect on osteoblast cell growth and collagen production. We can conclude that both bioactive coating and scaffold architecture type are the main factors to enhance the cell proliferation. These experimental results might have a great impact on the application possibilities of scaffolds in orthopedics as bioactive implants.

\section{Acknowledgments}

This paper was supported by H2020 Marie Skłodowska-Curie Actions (NanoSurf 777926), Ministry of Education and Science of Ukraine (0119U100823), Ukraine National Research Fund (2020.02/0223), and the Polish Ministry of Science and Higher Education (04/010/BK_20/0124).

\section{References}

[1] A.A. Zadpoor, Mechanical performance of additively manufactured meta-biomaterials, Acta Biomater. 85 (2019) 41-59. https://doi.org/10.1016/j.actbio.2018.12.038.

[2] H. Montazerian, M.G.A. Mohamed, M.M. Montazeri, S. Kheiri, A.S. Milani, K. Kim, M. Hoorfar, Permeability and mechanical properties of gradient porous PDMS 
scaffolds fabricated by 3D-printed sacrificial templates designed with minimal surfaces, Acta Biomater. 96 (2019) 149-160. https://doi.org/10.1016/j.actbio.2019.06.040.

[3] A. Boddupalli, D. Akilbekova, K.M. Bratlie, Poly-l-arginine modifications alter the organization and secretion of collagen in SKH1-E mice, Mater. Sci. Eng. C. 106 (2020) 110143. https://doi.org/10.1016/j.msec.2019.110143.

[4] S. Vijayavenkataraman, L.Y. Kuan, W.F. Lu, 3D-Printed Ceramic Triply Periodic Minimal Surface structures for design of functionally graded bone implants, Mater. Des. (2020) 108602. https://doi.org/10.1016/j.matdes.2020.108602.

[5] E. Chicardi, C.F. Gutiérrez-González, M.J. Sayagués, C. García-Garrido, Development of a novel TiNbTa material potentially suitable for bone replacement implants, Mater. Des. 145 (2018) 88-96. https://doi.org/10.1016/j.matdes.2018.02.042.

[6] J.Y. Rho, R.B. Ashman, C.H. Turner, Young's modulus of trabecular and cortical bone material: Ultrasonic and microtensile measurements, J. Biomech. 26 (1993) 111-119. https://doi.org/10.1016/0021-9290(93)90042-D.

[7] J. Breme, E. Eisenbarth, V. Biehl, Titanium and its Alloys for Medical Applications, in: Titan. Titan. Alloy., Wiley-VCH Verlag GmbH \& Co. KGaA, Weinheim, FRG, 2005: pp. 423-451. https://doi.org/10.1002/3527602119.ch16.

[8] M.I.Z. Ridzwan, S. Shuib., A.Y. Hassan., A.A. Shokri., M.N.M. Ibrahim., Problem of Stress Shielding and Improvement to the Hip Implant Designs: A Review, J. Med. Sci. 7 (2007) 460-467. https://doi.org/10.3923/jms.2007.460.467.

[9] H. Ibrahim, S.N. Esfahani, B. Poorganji, D. Dean, M. Elahinia, Resorbable bone fixation alloys, forming, and post-fabrication treatments, Mater. Sci. Eng. C. 70 (2017) 870-888. https://doi.org/10.1016/j.msec.2016.09.069.

[10] A. Shypylenko, A.V. Pshyk, B. Grześkowiak, K. Medjanik, B. Peplinska, K. Oyoshi, 
A. Pogrebnjak, S. Jurga, E. Coy, Effect of ion implantation on the physical and mechanical properties of Ti-Si-N multifunctional coatings for biomedical applications, Mater. Des. 110 (2016) 821-829. https://doi.org/10.1016/j.matdes.2016.08.050.

[11] A.D. Pogrebnjak, C.-H. Kong, R.F. Webster, R.D. Tilley, Y. Takeda, K. Oyoshi, O. V. Bondar, V. V. Buranich, S. V. Konstantinov, L.S. Baimoldanova, M. Opielak, P. Zukowski, P. Konarski, Antibacterial Effect of Au Implantation in Ductile Nanocomposite Multilayer (TiAlSiY)N/CrN Coatings, ACS Appl. Mater. Interfaces. 11 (2019) 48540-48550. https://doi.org/10.1021/acsami.9b16328.

[12] T. Femmer, A.J.C. Kuehne, M. Wessling, Estimation of the structure dependent performance of 3-D rapid prototyped membranes, Chem. Eng. J. 273 (2015) 438-445. https://doi.org/10.1016/j.cej.2015.03.029.

[13] S.J.P. Callens, R.J.C. Uyttendaele, L.E. Fratila-Apachitei, A.A. Zadpoor, Substrate curvature as a cue to guide spatiotemporal cell and tissue organization, Biomaterials. 232 (2020) 119739. https://doi.org/10.1016/j.biomaterials.2019.119739.

[14] M.D. Vlad, E. Fernández Aguado, S. Gómez González, I.C. Ivanov, E.V. Şindilar, I. Poeată, A.Ş. Iencean, M. Butnaru, E.R. Avădănei, J. López López, Novel titaniumapatite hybrid scaffolds with spongy bone-like micro architecture intended for spinal application: In vitro and in vivo study, Mater. Sci. Eng. C. 110 (2020) 110658. https://doi.org/10.1016/j.msec.2020.110658.

[15] F.S.L. Bobbert, K. Lietaert, A.A. Eftekhari, B. Pouran, S.M. Ahmadi, H. Weinans, A.A. Zadpoor, Additively manufactured metallic porous biomaterials based on minimal surfaces: A unique combination of topological, mechanical, and mass transport properties, Acta Biomater. 53 (2017) 572-584. https://doi.org/10.1016/j.actbio.2017.02.024.

[16] S. Bose, S.F. Robertson, A. Bandyopadhyay, Surface modification of biomaterials and 
biomedical devices using additive manufacturing, Acta Biomater. 66 (2018) 6-22. https://doi.org/10.1016/j.actbio.2017.11.003.

[17] M. Croes, S. Bakhshandeh, I.A.J. van Hengel, K. Lietaert, K.P.M. van Kessel, B. Pouran, B.C.H. van der Wal, H.C. Vogely, W. Van Hecke, A.C. Fluit, C.H.E. Boel, J. Alblas, A.A. Zadpoor, H. Weinans, S. Amin Yavari, Antibacterial and immunogenic behavior of silver coatings on additively manufactured porous titanium, Acta Biomater. 81 (2018) 315-327. https://doi.org/10.1016/j.actbio.2018.09.051.

[18] D. Melancon, Z.S. Bagheri, R.B. Johnston, L. Liu, M. Tanzer, D. Pasini, Mechanical characterization of structurally porous biomaterials built via additive manufacturing: experiments, predictive models, and design maps for load-bearing bone replacement implants, Acta Biomater. 63 (2017) 350-368. https://doi.org/10.1016/j.actbio.2017.09.013.

[19] Y. Li, W. Li, F.S.L. Bobbert, K. Lietaert, J.H. Dong, M.A. Leeflang, J. Zhou, A.A. Zadpoor, Corrosion fatigue behavior of additively manufactured biodegradable porous zinc, Acta Biomater. (2020). https://doi.org/10.1016/j.actbio.2020.02.001.

[20] D. Singh, A.J. Harding, E. Albadawi, F.M. Boissonade, J.W. Haycock, F. Claeyssens, Additive manufactured biodegradable poly(glycerol sebacate methacrylate) nerve guidance conduits, Acta Biomater. 78 (2018) 48-63. https://doi.org/10.1016/j.actbio.2018.07.055.

[21] G. Hannink, J.J.C. Arts, Bioresorbability, porosity and mechanical strength of bone substitutes : What is optimal for bone regeneration?, Injury. 42 (2011) S22-S25. https://doi.org/10.1016/j.injury.2011.06.008.

[22] N. Jiang, Z. Guo, D. Sun, Y. Li, Y. Yang, C. Chen, L. Zhang, S. Zhu, Promoting Osseointegration of Ti Implants through Micro/Nanoscaled Hierarchical Ti Phosphate/Ti Oxide Hybrid Coating, ACS Nano. 12 (2018) 7883-7891. 
https://doi.org/10.1021/acsnano.8b02227.

[23] J.W.C. Dunlop, F.D. Fischer, E. Gamsjäger, P. Fratzl, A theoretical model for tissue growth in confined geometries, J. Mech. Phys. Solids. 58 (2010) 1073-1087. https://doi.org/10.1016/j.jmps.2010.04.008.

[24] A.A. Zadpoor, Bone tissue regeneration: the role of scaffold geometry, Biomater. Sci. 3 (2015) 231-245. https://doi.org/10.1039/C4BM00291A.

[25] L. Li, J. Shi, K. Zhang, L. Yang, F. Yu, L. Zhu, H. Liang, X. Wang, Q. Jiang, Early osteointegration evaluation of porous Ti6Al4V scaffolds designed based on triply periodic minimal surface models, J. Orthop. Transl. 19 (2019) 94-105. https://doi.org/10.1016/j.jot.2019.03.003.

[26] M.J. Olszta, X. Cheng, S.S. Jee, R. Kumar, Y.-Y. Kim, M.J. Kaufman, E.P. Douglas, L.B. Gower, Bone structure and formation: A new perspective, Mater. Sci. Eng. R Reports. 58 (2007) 77-116. https://doi.org/10.1016/j.mser.2007.05.001.

[27] A. Turlybekuly, A.D. Pogrebnjak, L.F. Sukhodub, L.B. Sukhodub, A.S. Kistaubayeva, I.S. Savitskaya, D.H. Shokatayeva, O.V. Bondar, Z.K. Shaimardanov, S.V. Plotnikov, B.H. Shaimardanova, I. Digel, Synthesis, characterization, in vitro biocompatibility and antibacterial properties study of nanocomposite materials based on hydroxyapatitebiphasic $\mathrm{ZnO}$ micro- and nanoparticles embedded in Alginate matrix, Mater. Sci. Eng. C. 104 (2019) 109965. https://doi.org/10.1016/j.msec.2019.109965.

[28] A. Pogrebnjak, L. Sukhodub, L. Sukhodub, O. Bondar, M. Kumeda, B. Shaimardanova, Z. Shaimardanov, A. Turlybekuly, Composite material with nanoscale architecture based on bioapatite, sodium alginate and $\mathrm{ZnO}$ microparticles, Ceram. Int. 45 (2019) 7504-7514. https://doi.org/10.1016/j.ceramint.2019.01.043.

[29] A.D. Pogrebnjak, L.F. Sukhodub, L. Sukhodub, O. V. Bondar, A. Turlybekuly, ZnO Doped Nanosized Composite Material Based on Hydroxyapatite and Sodium Alginate 
Matrix, in: Adv. Thin Film. Nanostructured Mater. Coatings, 2019: pp. 361-368. https://doi.org/10.1007/978-981-13-6133-3_35.

[30] J. Niu, G. Yuan, Y. Liao, L. Mao, J. Zhang, Y. Wang, F. Huang, Y. Jiang, Y. He, W. Ding, Enhanced biocorrosion resistance and biocompatibility of degradable $\mathrm{Mg}-\mathrm{Nd}-$ Zn-Zr alloy by brushite coating, Mater. Sci. Eng. C. 33 (2013) 4833-4841. https://doi.org/10.1016/j.msec.2013.08.008.

[31] I. Bajpai, D.Y. Kim, J. Kyong-Jin, I.-H. Song, S. Kim, Effect of Water-Glass Coating on HA and HA-TCP Samples for MSCs Adhesion, Proliferation, and Differentiation, Biomed Res. Int. 2016 (2016) 1-8. https://doi.org/10.1155/2016/9758729.

[32] J. Zhao, K.H. Hwang, W.S. Choi, S.J. Shin, J.K. Lee, Biological Behavior of Osteoblast Cell and Apatite Forming Ability of the Surface Modified Ti Alloys, J. Nanosci. Nanotechnol. 16 (2016) 1541-1544. https://doi.org/10.1166/jnn.2016.11909.

[33] J. Zhou, X. Wang, L. Zhao, Antibacterial, angiogenic, and osteogenic activities of Ca, P, Co, F, and Sr compound doped titania coatings with different Sr content, Sci. Rep. 9 (2019) 14203. https://doi.org/10.1038/s41598-019-50496-3.

[34] A. Kazek-Kęsik, I. Kalemba-Rec, W. Simka, Anodization of a Medical-Grade Ti-6Al7Nb Alloy in a Ca(H2PO2)2-Hydroxyapatite Suspension, Materials (Basel). 12 (2019) 3002. https://doi.org/10.3390/ma12183002.

[35] X. Lu, M. Mohedano, C. Blawert, E. Matykina, R. Arrabal, K.U. Kainer, M.L. Zheludkevich, Plasma electrolytic oxidation coatings with particle additions - A review, Surf. Coatings Technol. 307 (2016) 1165-1182. https://doi.org/10.1016/j.surfcoat.2016.08.055.

[36] J. Duyck, K. Vandamme, L. Geris, H. Van Oosterwyck, M. De Cooman, J. Vandersloten, R. Puers, I. Naert, The influence of micro-motion on the tissue differentiation around immediately loaded cylindrical turned titanium implants, Arch. 
Oral Biol. 51 (2006) 1-9. https://doi.org/10.1016/j.archoralbio.2005.04.003.

[37] P. Zhang, Z. Zhang, W. Li, Antibacterial Coating Incorporating Silver Nanoparticles by Microarc Oxidation and Ion Implantation, J. Nanomater. 2013 (2013) 1-8. https://doi.org/10.1155/2013/542878.

[38] R.O. Darouiche, Treatment of Infections Associated with Surgical Implants, N. Engl. J. Med. 350 (2004) 1422-1429. https://doi.org/10.1056/NEJMra035415.

[39] G.-J.A. ter Boo, D.W. Grijpma, T.F. Moriarty, R.G. Richards, D. Eglin, Antimicrobial delivery systems for local infection prophylaxis in orthopedic- and trauma surgery, Biomaterials. 52 (2015) 113-125. https://doi.org/10.1016/j.biomaterials.2015.02.020.

[40] S. Prabhu, E.K. Poulose, Silver nanoparticles: mechanism of antimicrobial action, synthesis, medical applications, and toxicity effects, Int. Nano Lett. 2 (2012) 32. https://doi.org/10.1186/2228-5326-2-32.

[41] M. Breisch, V. Grasmik, K. Loza, K. Pappert, A. Rostek, N. Ziegler, A. Ludwig, M. Heggen, M. Epple, J.C. Tiller, T.A. Schildhauer, M. Köller, C. Sengstock, Bimetallic silver-platinum nanoparticles with combined osteo-promotive and antimicrobial activity, Nanotechnology. (2019). https://doi.org/10.1088/1361-6528/ab172b.

[42] R. Zhang, P. Lee, V.C.H. Lui, Y. Chen, X. Liu, C.N. Lok, M. To, K.W.K. Yeung, K.K.Y. Wong, Silver nanoparticles promote osteogenesis of mesenchymal stem cells and improve bone fracture healing in osteogenesis mechanism mouse model, Nanomedicine Nanotechnology, Biol. Med. (2015). https://doi.org/10.1016/j.nano.2015.07.016.

[43] Z. Gorgin Karaji, R. Hedayati, B. Pouran, I. Apachitei, A.A. Zadpoor, Effects of plasma electrolytic oxidation process on the mechanical properties of additively manufactured porous biomaterials, Mater. Sci. Eng. C. 76 (2017) 406-416. https://doi.org/10.1016/j.msec.2017.03.079. 
[44] P. Xiu, Z. Jia, J. Lv, C. Yin, H. Cai, C. Song, H. Leng, Y. Zheng, Z. Liu, Y. Cheng, Hierarchical Micropore/Nanorod Apatite Hybrids In-Situ Grown from 3-D Printed Macroporous Ti6Al4V Implants with Improved Bioactivity and Osseointegration, J. Mater. Sci. Technol. 33 (2017) 179-186. https://doi.org/10.1016/j.jmst.2016.05.013.

[45] P. Joly, G.N. Duda, M. Schöne, P.B. Welzel, U. Freudenberg, C. Werner, A. Petersen, Geometry-Driven Cell Organization Determines Tissue Growths in Scaffold Pores: Consequences for Fibronectin Organization, PLoS One. 8 (2013) e73545. https://doi.org/10.1371/journal.pone.0073545.

[46] V. KARAGEORGIOU, D. KAPLAN, Porosity of 3D biomaterial scaffolds and osteogenesis, Biomaterials. 26 (2005) 5474-5491. https://doi.org/10.1016/j.biomaterials.2005.02.002.

[47] T. Femmer, A.J.C. Kuehne, M. Wessling, Estimation of the structure dependent performance of 3-D rapid prototyped membranes, Chem. Eng. J. 273 (2015) 438-445. https://doi.org/10.1016/j.cej.2015.03.029.

[48] A.H. Schoen, Infinite periodic minimal surfaces without self-intersections, Cambridge, MA, United States, 1970.

[49] E.A. Lord, A.L. Mackay, Periodic minimal surfaces of cubic symmetry, Curr. Sci. 85 (2003) 346-362.

[50] K. Leśniak-Ziółkowska, A. Kazek-Kęsik, K. Rokosz, S. Raaen, A. Stolarczyk, M. Krok-Borkowicz, E. Pamuła, M. Gołda-Cępa, M. Brzychczy-Włoch, W. Simka, Electrochemical modification of the Ti-15Mo alloy surface in solutions containing $\mathrm{ZnO}$ and Zn3(PO4)2 particles, Mater. Sci. Eng. C. 115 (2020) 111098. https://doi.org/10.1016/j.msec.2020.111098.

[51] O. Oleshko, I. Liubchak, Y. Husak, V. Korniienko, A. Yusupova, T. Oleshko, R. Banasiuk, M. Szkodo, I. Matros-Taranets, A. Kazek-Kęsik, W. Simka, M. Pogorielov, 
In Vitro Biological Characterization of Silver-Doped Anodic Oxide Coating on Titanium, Materials (Basel). 13 (2020) 4359. https://doi.org/10.3390/ma13194359.

[52] Z. Fan, H. Feng, Study on selective laser melting and heat treatment of Ti-6Al-4V alloy, Results Phys. 10 (2018) 660-664. https://doi.org/10.1016/j.rinp.2018.07.008.

[53] X. Tan, Y. Kok, W.Q. Toh, Y.J. Tan, M. Descoins, D. Mangelinck, S.B. Tor, K.F. Leong, C.K. Chua, Revealing martensitic transformation and $\alpha / \beta$ interface evolution in electron beam melting three-dimensional-printed Ti-6Al-4V, Sci. Rep. 6 (2016) 26039. https://doi.org/10.1038/srep26039.

[54] B. Wysocki, P. Maj, A. Krawczyńska, K. Rożniatowski, J. Zdunek, K.J. Kurzydłowski, W. Święszkowski, Microstructure and mechanical properties investigation of CP titanium processed by selective laser melting (SLM), J. Mater. Process. Technol. 241 (2017) 13-23. https://doi.org/10.1016/j.jmatprotec.2016.10.022.

[55] C. Yan, L. Hao, A. Hussein, P. Young, Ti-6Al-4V triply periodic minimal surface structures for bone implants fabricated via selective laser melting, J. Mech. Behav. Biomed. Mater. 51 (2015) 61-73. https://doi.org/10.1016/j.jmbbm.2015.06.024.

[56] R. Havaldar, S. Pilli, B. Putti, Insights into the effects of tensile and compressive loadings on human femur bone, Adv. Biomed. Res. 3 (2014) 101. https://doi.org/10.4103/2277-9175.129375.

[57] S. Durdu, Ö.F. Deniz, I. Kutbay, M. Usta, Characterization and formation of hydroxyapatite on Ti6Al4V coated by plasma electrolytic oxidation, J. Alloys Compd. 551 (2013) 422-429. https://doi.org/10.1016/j.jallcom.2012.11.024.

[58] R.C. Barik, J.A. Wharton, R.J.K. Wood, K.R. Stokes, R.L. Jones, Corrosion, erosion and erosion-corrosion performance of plasma electrolytic oxidation (PEO) deposited A12O3 coatings, Surf. Coatings Technol. 199 (2005) 158-167. https://doi.org/10.1016/j.surfcoat.2004.09.038. 
[59] D. Krishnamurti, The Raman spectrum of rutile, Proc. Indian Acad. Sci. - Sect. A. 55 (1962) 290-299. https://doi.org/10.1007/BF03045870.

[60] G.A. Tompsett, G.A. Bowmaker, R.P. Cooney, J.B. Metson, K.A. Rodgers, J.M. Seakins, The Raman spectrum of brookite, TiO2 (Pbca, Z = 8), J. Raman Spectrosc. 26 (1995) 57-62. https://doi.org/10.1002/jrs.1250260110.

[61] V. Štengl, T.M. Grygar, J. Henych, M. Kormunda, Hydrogen peroxide route to Sndoped titania photocatalysts, Chem. Cent. J. 6 (2012) 113. https://doi.org/10.1186/1752-153X-6-113.

[62] T. Ohsaka, F. Izumi, Y. Fujiki, Raman spectrum of anatase, TiO2, J. Raman Spectrosc. 7 (1978) 321-324. https://doi.org/10.1002/jrs.1250070606.

[63] I. Martina, R. Wiesinger, M. Schreiner, Micro-Raman Characterisation of Silver Corrosion Products : Instrumental Set Up and Reference, E-Preservation Sci. (2012).

[64] M.L.A. Temperini, G.I. Lacconi, O. Sala, Raman spectroscopy investigation of the silver oxide/silver electrode, J. Electroanal. Chem. Interfacial Electrochem. 227 (1987) 21-28. https://doi.org/10.1016/0022-0728(87)80062-1.

[65] O. Oleshko, V. Deineka V, Y. Husak, V. Korniienko, O. Mishchenko, V. Holubnycha, M. Pisarek, J. Michalska, A. Kazek-Kęsik, A. Jakóbik-Kolon, W. Simka, M. Pogorielov, Ag Nanoparticle-Decorated Oxide Coatings Formed via Plasma Electrolytic Oxidation on ZrNb Alloy, Materials (Basel). 12 (2019) 3742. https://doi.org/10.3390/ma12223742.

[66] S. Kyrylenko, F. Warchoł, O. Oleshko, Y. Husak, A. Kazek-Kęsik, V. Korniienko, V. Deineka, M. Sowa, A. Maciej, J. Michalska, A. Jakóbik-Kolon, I. Matuła, M. Basiaga, V. Hulubnycha, A. Stolarczyk, M. Pisarek, O. Mishchenko, M. Pogorielov, W. Simka, Effects of the sources of calcium and phosphorus on the structural and functional properties of ceramic coatings on titanium dental implants produced by plasma 
electrolytic oxidation, Mater. Sci. Eng. C. 119 (2021) 111607.

https://doi.org/10.1016/j.msec.2020.111607.

[67] M. Sowa, M. Parafiniuk, C.M.S. Mouzêlo, A. Kazek-Kęsik, I.S. Zhidkov, A.I. Kukharenko, S.O. Cholakh, E.Z. Kurmaev, W. Simka, DC plasma electrolytic oxidation treatment of gum metal for dental implants, Electrochim. Acta. 302 (2019) 10-20. https://doi.org/10.1016/j.electacta.2019.02.024.

[68] H.J. Robinson, A.E. Markaki, C.A. Collier, T.W. Clyne, Cell adhesion to plasma electrolytic oxidation (PEO) titania coatings, assessed using a centrifuging technique, J. Mech. Behav. Biomed. Mater. 4 (2011) 2103-2112. https://doi.org/10.1016/j.jmbbm.2011.07.009.

[69] E. Tamjid, A. Simchi, J.W.C. Dunlop, P. Fratzl, R. Bagheri, M. Vossoughi, Tissue growth into three-dimensional composite scaffolds with controlled micro-features and nanotopographical surfaces, J. Biomed. Mater. Res. Part A. 101 (2013) 2796-2807. https://doi.org/10.1002/jbm.a.34584.

[70] P. Joly, G.N. Duda, M. Schöne, P.B. Welzel, U. Freudenberg, C. Werner, A. Petersen, Geometry-Driven Cell Organization Determines Tissue Growths in Scaffold Pores: Consequences for Fibronectin Organization, PLoS One. 8 (2013) e73545. https://doi.org/10.1371/journal.pone.0073545.

[71] A. Scarano, V. Perrotti, L. Artese, M. Degidi, D. Degidi, A. Piattelli, G. Iezzi, Blood vessels are concentrated within the implant surface concavities: a histologic study in rabbit tibia, Odontology. 102 (2014) 259-266. https://doi.org/10.1007/s10266-0130116-3.

[72] M. Paolo, M. Santos, B. Cimatti, N. Gava, M. Riberto, E. Engel, Osteointegration of porous absorbable bone substitutes: A systematic review of the literature, Clinics. 72 (2017) 449-453. https://doi.org/10.6061/clinics/2017(07)10. 
[73] C.E. Tanase, M. Golozar, S.M. Best, R.A. Brooks, Cell response to plasma electrolytic oxidation surface-modified low-modulus $\beta$-type titanium alloys, Colloids Surfaces B Biointerfaces. 176 (2019) 176-184. https://doi.org/10.1016/j.colsurfb.2018.12.064.

[74] M.J.P. Biggs, R.G. Richards, M.J. Dalby, Nanotopographical modification: a regulator of cellular function through focal adhesions, Nanomedicine Nanotechnology, Biol. Med. 6 (2010) 619-633. https://doi.org/10.1016/j.nano.2010.01.009.

[75] J.A. Sanz-Herrera, P. Moreo, J.M. García-Aznar, M. Doblaré, On the effect of substrate curvature on cell mechanics, Biomaterials. 30 (2009) 6674-6686. https://doi.org/10.1016/j.biomaterials.2009.08.053.

[76] E. Tamjid, A. Simchi, J.W.C. Dunlop, P. Fratzl, R. Bagheri, M. Vossoughi, Tissue growth into three-dimensional composite scaffolds with controlled micro-features and nanotopographical surfaces, J. Biomed. Mater. Res. Part A. 101 (2013) 2796-2807. https://doi.org/10.1002/jbm.a.34584. 